\title{
Adverse Effects of Nonsteroidal Antiinflammatory Drugs: An Update of Gastrointestinal, Cardiovascular and Renal Complications ${ }^{\dagger}$
}

\author{
Sam Harirforoosh ${ }^{1}$, Waheed Asghar ${ }^{2}$, and Fakhreddin Jamali ${ }^{2}$ \\ ${ }^{1}$ Department of Pharmaceutical Sciences, Gatton College of Pharmacy, East Tennessee State University, Johnson City, TN, \\ USA; ${ }^{2}$ Faculty of Pharmacy and Pharmaceutical Sciences, University of Alberta, Edmonton, Alberta, Canada
}

Received, October 15, 2013; Revised, December 11, 2013; Accepted, December 23, 2013; Published, December 31, 2013

\begin{abstract}
Non-steroidal anti-inflammatory drugs (NSAIDs) are used chronically to reduce pain and inflammation in patients with arthritic conditions, and also acutely as analgesics by many patients. Both therapeutic and adverse effects of NSAIDs are due to inhibition of cyclooxygenase (COX) enzyme. NSAIDs are classified as non-selective and COX-2-selective inhibitors (COXIBS) based on their extent of selectivity for COX inhibition. However, regardless of their COX selectivity, reports are still appearing on the GI side effect of NSAIDs particularly on the lower gastrointestinal (GI) tract and the harmful role of their controlled release formulations. In addition, previously unpublished data stored in the sponsor's files, question the GI sparing properties of rofecoxib, a COXIB that has been withdrawn due to cardiovascular (CV) side effects. Presently, the major side effects of NSAIDs are the GI complications, renal disturbances and CV events. There is a tendency to believe that all NSAIDs are associated with renal and CV side effects, a belief that is not supported by solid evidence. Indeed, lower but still therapeutics doses of some NSAIDs may be cardioprotective. In this review, we briefly discuss the GI toxicity of the NSAIDs and assess their renal and CV adverse effects in more detail.
\end{abstract}

This article is open to POST-PUBLICATION REVIEW. Registered readers (see "For Readers") may comment by clicking on ABSTRACT on the issue's contents page.

\section{List of Contents}

1. Introduction

1.1. Classification of NSAIDs

1.2. Therapeutic Use of NSAIDs

1.3. Mechanism of Action of NSAIDs

2. Literature Search Strategy

2.1. Literature Limitations

3. Adverse Effects of NSAIDs

3.1. Gastrointestinal Side Effects

3.1.1. Minor GI Side Effects

3.1.2. Serious GI Side Effects

3.1.3. Treatment and Prevention Strategies

3.1.4. Traditional NSAIDs verses COXIBs

3.1.5. Summary of GI Side Effects

3.2. Renal Side Effects

3.2.1. Glomerular Filtration

3.2.2. Acute Renal Failure

3.2.3. Renal Papillary Necrosis

3.2.4. Nephrotic Syndrome with Acute Interstitial Nephritis

3.2.5. Electrolyte and Fluid Retention

3.2.6. Chronic Renal Failure

3.2.7. Hypertension Caused by Electrolyte Retention

3.2.8. Summary of NSAIDs Renal Effects

3.3. Cardiovascular and Cerebrovascular Effects
3.3.1. Composite Cardiac Outcome; COXIBS vs. Non-Selective NSAIDs

3.3.2. Effect of Duration of Treatment

3.3.3. Dose-dependency of CV Side Effects

3.3.4. Risk of Cardiac Death, All-Cause Mortality

3.3.5. Risk of Myocardial Infarction

3.3.6. Risk of Cardiogenic Stroke

3.3.7. Risk of Thromboembolic Event

3.3.8 Risk of Atrial Fibrillation

3.3.9 Risk of Elevated Blood Pressure and Hypertension

4. Conclusion

5. Anticipated Advances in the Knowledge of the Field

6. References

${ }^{\dagger}$ Dedicated to the memory of Tahereh Khazaeinia, $\mathrm{PhD}$ (1956-2013), who played a significant role in the development of the concepts expressed herein.

Correspondence Authors: F. Jamali, Faculty of Pharmacy \& Pharmaceutical Sciences, University of Alberta, Edmonton, Alberta, Canada, T6G 2E1; fjamali@ualberta.ca, or S. Harirforoosh, Gatton College of Pharmacy, East Tennessee State University, Box 70594, Johnson City, TN 37614-1708; harirfor@etsu.edu. 


\begin{tabular}{|c|c|}
\hline \multicolumn{2}{|c|}{ Abbreviations } \\
\hline $\mathrm{AF}$ & Atrial fibrillation \\
\hline AIN & Acute interstation nephritis \\
\hline ARF & Acute renal failure \\
\hline APPROVe & Adenomatous Polyp Prevention on Vioxx \\
\hline ASA & Acetyl salicylic acid, Aspirin \\
\hline BUN & Blood urea nitrogen \\
\hline CLASS & Celecoxib Long Term Arthritis Safety Study \\
\hline $\mathrm{COX}$ & Cyclooxygenase \\
\hline COXIBs & Cyclooxygenase-2-selective Inhibitors \\
\hline CRF & Chronic renal failure \\
\hline $\mathrm{CV}$ & Cardiovascular \\
\hline EP & Prostaglandin-E receptor \\
\hline GFR & Glomerular filtration rate \\
\hline GI, & Gastrointestinal \\
\hline HETE & Hydroxy eicosatetraenoic acid \\
\hline $\mathrm{HF}$ & Heart failure \\
\hline MEDAL & $\begin{array}{l}\text { Multinational Etoricoxib and Diclofenac Arthritis } \\
\text { Long-term }\end{array}$ \\
\hline MI & Myocardial infarction \\
\hline NSAIDs & Nonsteroidal antiinflammatory drugs \\
\hline $\mathrm{OA}$ & Osteoarthritis \\
\hline OATP & Organic anion transporting polypeptide \\
\hline OR & Odds ratio \\
\hline PG & Prostaglandin \\
\hline PRECISION & $\begin{array}{l}\text { Prospective Randomized Evaluation of Celecoxib } \\
\text { Integrated Safety versus Ibuprofen or Naproxen }\end{array}$ \\
\hline RA & Rheumatoid arthritis \\
\hline RCT & Randomized Control Trials \\
\hline RPN & Renal papillae necrosis \\
\hline $\mathrm{RR}$ & Relative risk \\
\hline SCOT & Standard Care versus Celecoxib Outcome Trial \\
\hline TXA & Thromboxane A \\
\hline VIGOR & Vioxx Gastrointestinal Outcomes Research \\
\hline
\end{tabular}

\section{INTRODUCTION}

Non-steroidal antiinflammatory drugs (NSAIDs) are one of the most commonly used groups of drugs. They are a diverse group of compounds that possess analgesic, antipyretic and antiinflammatory effects (1). Acetylsalicylic acid (ASA) was the first NSAIDs introduced to the market in 1899 under the name of Aspirin (2). Indomethacin and ibuprofen were the first non-ASA NSAIDs made in 1964 and 1969 respectively (3). Since then, many new compounds belonging to various classes of organic acids with similar therapeutic effects have been developed (2). Many patients, particularly those with arthritis, are the daily users of NSAIDs (4). It is estimated that globally approximately seven billion dollars is spent on NSAIDs per year that makes upto $2.5 \%$ of all the prescription dollars in the world (5). Among various NSAIDs, diclofenac is the most commonly used NSAID worldwide (6).

Most NSAIDs are acidic compounds with a relatively high bioavailability. They are highly bound to plasma proteins and are metabolized by the liver $(4,7)$. Glucuronidation by the kidney enzyme is also reported for some NSAIDs (e.g., naproxen, ibuprofen, ketoprofen) (7, 8). Most patients take therapeutic doses of these drugs for short durations and, usually, tolerate them well (9). The gastrointestinal (GI), renal and cardiovascular (CV) side effects limit NSAIDs use (10). Thus, in addition to the obvious commercial interest, the purpose of the development of new drugs has always been to introduce medications with greater efficacy but fewer side effects (11). We have previously discussed the effects of NSAIDs on the renal system (4). The present article provides an updated review of NSAIDs' GI, renal and CV side effects with more emphasis on what has been reported since 2009.

\subsection{Classification of NSAIDs}

NSAIDs are categorized in different ways such as classification based on chemical structure (i.e. Table 1) (12) or based on selective inhibition of cyclooxygenase enzymes (i.e. Table 2) (13). The COX-2 selectivity of NSAIDs is reported differently depending on the method used. However, in general, NSAIDs are divided into two major groups: cyclooxygenase (COX) -2-selective inhibitors (COXIBs) and non-selective NSAIDs.

Many NSAIDs have a chiral structure. Of those, only naproxen has been available as a single pharmacologically active enantiomer (Table 1). Other chiral NSAIDs are available as racemates with the main antiinflammatory and analgesic activities attributed to the $S$ enantiomer (14). In some countries $\mathrm{S}$-ibuprofen is also available. In humans, the $\mathrm{R}$ enantiomer of some of the chiral NSAIDs is metabolized to the $\mathrm{S}$ enantiomer (15). In some species this enantiomeric inversion can be bidirectional (16).

\subsection{Therapeutic Use of NSAIDs}

NSAIDs are used to relieve pain and discomfort associated with chronic conditions such as rheumatoid arthritis (RA) (17) and osteoarthritis (OA) (18). Some of NSAIDs, including ASA, are also indicated for other conditions such as juvenile arthritis, psoriatic arthritis, Reiter's syndrome, systemic lupus erythematosus, rheumatic fever, thrombosis, pericarditis, Kawasaki disease, gout, gouty arthritis, ankylosing spondylitis, patent ductus arteriosus and dysmenorrhea (19). They are also used to prevent colon cancer (20) and Alzheimer's disease (21) although their latter action has not been unequivocally confirmed (22). 
Table 1. Chemical classification of NSAIDs

\begin{tabular}{|c|c|}
\hline Group & Example(s) \\
\hline Salicylates & $\begin{array}{l}\text { Acetyl salicylic acid, } \\
\text { sulfasalazine }\end{array}$ \\
\hline Propionic acid derivatives & $\begin{array}{l}\text { Ibuprofen*, naproxen*, } \\
\text { ketoprofen*, flurbiprofen, } \\
\text { fenoprofen, Oxaprozin. }\end{array}$ \\
\hline Pyranocarboxylic acids & Etodolac* \\
\hline Heteroaryl acetic acid & $\begin{array}{l}\text { Tolmetin, diclofenac, } \\
\text { ketorolac* }\end{array}$ \\
\hline Alkanones & Nabumetone \\
\hline Indoleacetic, Indeneacetic acids & $\begin{array}{l}\text { Indomethacin, sulindac, } \\
\text { etodolac* }\end{array}$ \\
\hline Oxicams & Piroxicam, meloxicam \\
\hline Pyrroloppyrrole & Ketorolac* \\
\hline Fenamates & $\begin{array}{l}\text { Mefenamic acid, meclofenamic } \\
\text { acid }\end{array}$ \\
\hline Diaryheterocycles (COXIBs) & $\begin{array}{l}\text { Rofecoxib, celecoxib, } \\
\text { veldecoxib, paracoxib, } \\
\text { etoricoxib, lumaricoxib }\end{array}$ \\
\hline
\end{tabular}

\subsection{Mechanism of Action of NSAIDs}

The mechanism of action of NSAIDs was first described in 1971 by Vane and Piper who demonstrated that NSAIDs actually exert their effects through inhibition of prostaglandin and prostanoids biosynthesis by COX enzymes (3). Prostanoids including prostaglandins (PGs), prostacyclins and thromboxanes are inflammatory mediators that are derived from arachidonic acid in a series of reactions known as arachidonic acid cascade (23). COX isozymes are the first to convert arachidonic acid to prostaglandin (PG) G2 (4). Then, peroxidase metabolizes $\mathrm{PGG}_{2}$ to $\mathrm{PGH}_{2}$ which is, in turn, converted by tissue-specific isomerases to primary prostanoids including $\mathrm{PGD}_{2}, \mathrm{PGE}_{2}$, $\mathrm{PGF}_{2 \alpha}, \mathrm{PGI}_{2}$, and thromboxane $\mathrm{A}_{2}$. Both therapeutic and adverse effects of NSAIDs are caused through inhibition of COX enzyme (2) and consequent blocking of the formation of PG and related compounds. Analgesic, antipyretic, and antiinflammatory effects of NSAIDs are attributed to the reduction in production of $\mathrm{PGE}_{2}$ and $\mathrm{PGI}_{2}$ (24). Two isoforms of COX (COX-1 and COX-2) have been discovered in 1991 (25-27). Recently a new variant of COX-1 denoted by COX-3 has been identified (28). However, its role has not been well understood (29).

The selectivity of NSAIDs to inhibit the two COX enzymes is suggested, at least in theory, to govern their toxic profile (13). An inhibition of COX-2, the "inducible" enzyme blocks the conversion of arachidonic acid to inflammatory PGs that is thought to be the key to the most beneficial antiinflammatory effects of NSAIDs. An inhibition of COX-1, the "constitutive" enzyme, on the other hand, results in altered cell integrity that may cause GI side effects. In the meantime the ASA-like CV protection properties of NSAIDs are attributed to their COX-1 inhibitory action (27).

Table.2. Ranking of a selected group of NSAIDs based on their COX-1 or COX-2 selectivity

\begin{tabular}{lc}
\hline NSAID & COX-1 \\
\hline Ketorolac & 1 \\
Flurbiprofen & 2 \\
Ketoprofen & 3 \\
Indomethacin & 4 \\
Acetylsalicylic acid & 5 \\
Naproxen & 6 \\
Tolmetin & 7 \\
Ibuprofen & 7 \\
\hline & COX-2 \\
\hline Rofecoxib & 1 \\
Etodolac & 2 \\
Meloxicam & 3 \\
Celecoxib & 4 \\
Diclofenac & 5 \\
Sulindac & 6 \\
Meclofenamate & 7 \\
Piroxicam & 7 \\
Diflunisal & 8 \\
Sodium salicylate & 9 \\
\hline Adopted from reference 13 with modifications. &
\end{tabular}

A change in the balance between COX-1 and COX-2 activities in the body has been suggested to influence, at least in part, the adverse effects including GI complications, reduced renal output, bleeding disorder and cardiogenic events (30). In addition, investigators have proposed possible physiochemical properties (i.e., ionization constant, pKa, solubility, partition coefficients) determining the distribution of these drugs in the body tissues, to be the reason for the differential toxic effects of these NSAIDs $(31,32)$.

In humans, both $\mathrm{COX}-1$ and $\mathrm{COX}-2$ are expressed in many tissues despite the initial thought that COX-2 was generally absent in normal tissues but induced only by inflammatory stimuli $(33,34)$. COX-2 is also involved in development of kidneys (35).

Recently, an ion channel hypothesis has been postulated suggestive of a $\mathrm{Ca}++$ induced $\mathrm{K}+$ channels to be the target of most NSAIDs for their 
side effects. The differential ability of the NSAIDs to affect these ion channels is thought to be the key to the differential nature of their pharmacological actions as well as their adverse effects such as their cardiotoxicity (39). Similarly, a pH-dependent iontrapping property of an NSAID in acidotic tissues may affect its GI toxicity, its selectivity and efficacy under inflammatory conditions $(40,41)$.

Some authors have suggested a role for the drug transporters in determining the differential safety and efficacy profile of NSAIDs. One such hypothesis is the differential effect of COXIBs on the organic anion transporting polypeptide 2A1 (OATP2A1), a prostaglandin transporter found principally in the GI tract. These transporters may have a role in determining the GI tract safety profile of NSAIDs as they are inhibited to a varying degree by these drugs (42).

Most side effects of NSAIDs are associated with inflammation, a condition that, they ironically are intended to reverse. For example, the GI side effects of NSAIDs are associated with excessive expression of inducible nitric oxide and other reactive molecules (43) that are implicated in inflammatory conditions. These chemicals are involved in various $\mathrm{CV}$ conditions caused by NSAIDs (44).

There is controversy as to whether the CV risks associated with NSAIDS can be assumed for the entire class of NSAIDs (29). Some investigators have suggested that toxic NSAIDs, e.g., rofecoxib, increase the susceptibility of the cardiomyocytes membrane to oxidative damage (45). Others have applied a metabolomics approach and have suggested a many fold increase in the plasma of mice treated with rofecoxib of an arachidonic acid metabolite, 20-hydroxyeicosatetraenoic acid (20HETE) (46). We have not been able to reproduce this experiment using rats in our laboratory. Checking the issue from epidemiologic viewpoint, a recent meta-analysis has suggested that the magnitude of the risk of CV event can be predicted by monitoring the atherothrombotic vascular events in NSAIDs users (47).

Initially only celecoxib, meloxicam and rofecoxib were recognized as the first generation of COXIBs with the latter being the most selective one. However, it is now known that some traditional NSAIDs such as etodolac, diclofenac and sulindac also possess high $\mathrm{COX}-2 / \mathrm{COX}-1$ inhibitory properties (Table 2) (13).

\section{LITERATURE SEARCH STRATEGY}

This work was not intended to be a systematic review; hence, our search was not exhaustive. To avoid redundancy, we only highlight representative studies with the aim of bringing to the reader's attention the main learning from the vast literature available on the issue. We carried out a comprehensive search on Medline. We used Ovid and PubMed mesh database and looked for studies reporting the GI, renal and $\mathrm{CV}$ outcomes in NSAIDs user.

\subsection{Literature Limitations}

The literature is crowded with contradicting reports on the subject rendering a reasonable conclusion difficult. There are mainly three types of reports: Randomized control trials (RCT), epidemiological analysis and reviews including meta-analysis. The RCT studies, although most robust, may suffer from methodological limitations such as patients heterogeneity, questionable and imprecise clinical metrics, and industry bias; e.g., unpublished data kept in the Company's files. In addition, RCT studies may be criticized for their control conditions; i.e., not including the "real world" patients.

The epidemiological studies, typically, analyze data collected from the real world patients. They can be retrospective or prospective in design. Nevertheless, data collection by various centers may introduce great variability in the outcomes and also include patient heterogeneity depending on the inclusion/exclusion criteria. It is not uncommon to find studies that patient's condition is ignored as a variant (e.g., 48). In addition, most studies are not placebo-controlled and, instead, compare the side effect of the test drug with another drug that is presumed to be safe or used as reference (e.g., celecoxib vs other NSAIDs, 49). Subsequent studies to test the drug against placebo, therefore, may challenge the safety of the "safe" drug (e.g., celecoxib) (50).

The meta-analysis and systematic reviews are as reliable as the source of information; i.e., RCT and epidemiological data. A mere meta-analysis approach will not improve the quality of data collected by the sources. Meta-analyses are also prone to heterogeneity of patients which is a consequence of the assumptions used for each study 
to include and/or exclude data. Lack of access to unpublished data kept in the sponsor's records is another source of bias for meta-analysis. A common source of variability in results that is shared by all three approaches is the inclusion/exclusion criteria and the statistical methods used. The same set of data can be interpreted differently when a different statistical approach is taken or a subgroup is excluded.

Other complicating factor that appear as an obstacle in drawing conclusions based on some reviews and epidemiological studies include the omission of the size of the dose, the pharmaceutical dosage form and the inclusion of all members of the NSAIDs class in the same group. For example, some studies have made observations on a single NSAID and have generalized it to the entire class (e.g., 51). This is while there are clear indications that all these factors play important roles in the side effects of NSAIDs.

\section{ADVERSE EFFECTS OF NSAIDS}

NSAIDs have a range of adverse effects mainly affecting the GI, renal and CV systems (10). However, the majority of the patients taking therapeutic doses of these NSAIDs and for shorter duration usually tolerate them well (9). However, with longer duration of treatment and in the presence of comorbidities higher risk may emerge. Overall, the treatment with NSAIDs is complex as it involves a decision based of risk:benefit ratio according to the patient's current condition.

\subsection{Gastrointestinal Side Effects \\ 3.1.1. Minor GI Side Effects}

The most common side effect of NSAIDs is reported to be mild events such as dyspepsia, heartburn and nausea (52). Most of these GI adverse effects are limited to the upper GI tract. They are readily noticeable by the patient, and are readily diagnosed at the clinic. The effectiveness of various gastro-duodenal-protective approaches to control upper GI side effects of NSAIDs has been reported (53-57).

\subsubsection{Serious GI Side Effects}

The upper GI complication of NSAIDs are wellknown, however, the less frequent but potentially more serious toxic effect of NSAIDs which occurs in the more distal segments of the GI tract is often ignored. In contrast to the upper GI complications that are often noticed by the patient, the lower GI side effects of NSAIDs are not readily detectable, hence, limited efforts toward their control are made (43). This harmful effect of NSAIDs may result in serious conditions (58) that range from lesions to stricture of the lumen called the diaphragm disease (59). All NSAIDs may casus the distal GI side effect although with varying intensity $(60,61)$. Even the low dose ASA regimens are not excluded from this side effect (62-63). It is important to note that the risk of distal GI toxicity of NSAIDs appear to increase with formulations that are designed to release in the intestine; e.g., enteric coated and sustained release $(64,65)$. Indeed, based on some data generated using animal models, it appears that the use of the latter formulations may shift the GI side effect of NSAIDs from the readily detectable upper segments to the less accessible lower part of the tract (65) unless the drug is void of potent local effects (66). One may ascribe some benefits to the enteric coated NSAIDs, i.e., less gastric irritation, but the use of sustained-release formulation of these drugs are without any therapeutic rationale.

\subsubsection{Treatment and Prevention Strategies}

Several factors including a history of GI damage, age over 60 years, high exposure to NSAIDs, and/or drug interactions with corticosteroids or anticoagulants increase the risk of developing GI side effects (67). Concomitant use of mucosal protective agents (e.g., rebamipide or misoprostol) $(53,68,69), \mathrm{H}_{2}$ receptor antagonists (e.g., ranitidine and famotidine) (70), or proton pump inhibitors (e.g., omeprazole) (71) can be utilized to reduce the gastric or intestinal damages induced by NSAIDs. These treatments, except for misoprostol (72) and, perhaps, rebamipide $(68,69)$, however, are mainly directed toward the side effects that are detected in the upper GI tract and their effectiveness in protecting the lower segments of the tract is not proven. Metronidazole due, perhaps, to its freeradical scavenging property, appear to protect the GI tract against the NSAIDs induced damages (43). However, such a treatment does not seem reasonable due to the risk of bacterial resistance. Nevertheless, it is suggested that protective strategies to be considered when NSAIDs are being prescribed regardless of the length of treatment (73).

Topical NSAIDs have become popular among OA patients. A review of the available 
clinical trials suggests that head-to-head comparisons of topical and oral NSAIDs produce similar efficacy with less GI side effects in patients receiving topical NSAIDs as compared with those using oral formulations $(74,75)$. In addition to the documented skin irritation (74), the CV and renal safety profile of topical NSAIDs remains to be assessed. However, the lower systemic exposure that is expected from topical usage may result in a better overall safety profile for them.

\subsubsection{Traditional NSAIDs versus COXIBs}

Celecoxib has been shown to be associated with minimal GI complications (76). Also, a metaanalysis of nine randomized clinical trials comparing celecoxib with non-selective NSAIDs found less GI side effects associated with the former (51). Unfortunately, some authors (e.g., 51), who studied one COXIB, extrapolate their finding to the entire class. For example it is important to learn that a revisit of the unpublished data made available as part of litigation on the GI side effects of rofecoxib has failed to confirm a GI safety advantage for the drug over the traditional NSAIDs (77). The authors state that "it is widely believed and cited that rofecoxib use is associated with approximately a 50\% reduction in significant GI complications such as bleeding." Indeed, a review of data collected since the withdrawal of rofecoxib suggests no decrease in incidence of GI side effects for the latter as compared with other NSAIDs (78). The existence of unpublished data that suggests results contrary to the published reports is a clear indicative of industry bias and may be more common than this very publicized and litigious case. Based on only the published data, celecoxib still causes GI intolerance in aged patients albeit lower than other NSAIDs (17\% vs $21-30 \%$ ) (79).

\subsubsection{Summary of GI Side Effects}

Overall, all NSAIDs may cause GI side effects with celecoxib potentially associated with less risk as compared with other tested NSAIDs. Detailed studies focused on other potentially safe NSAIDs such as etodolac and meloxicam are lacking. It is unclear whether the relatively safer risk of celecoxib is due to its COX-2 inhibitory selectivity since rofecoxib does not appear to be safer that other NSAIDs. Detailed RCT studies are lacking for other NSAIDs with favorable COX-2 selectivity and potentially safer GI safety. The concomitant use of GI protective drugs, particularly, misoprostol, appear to minimize the GI side effects. There is no rationale for the use of modified release formulations of NSAIDs that may cause side effect in the lower GI. Topical NSAIDs can be considered as preferred medications for conditions such as OA.

\subsection{Renal Side Effects}

It is estimated that $1-5 \%$ of NSAIDs users may develop renal adverse effects (4). Both acute (ARF) and chronic (CRF) renal failure can be caused by NSAIDs (80). Various forms of renal failures caused by NSAIDs have been observed including acute deterioration of renal function, renal papillary necrosis, acute interstitial nephritis, hyperkalemia and sodium and fluid retention $(81,82)$. Acute form of these side effects are dose/duration-dependent and usually reversible. However, sometimes they result in chronic renal failure. Indeed, it appears that a history of acute renal failure renders the patient more prone to the chronic version of the complication (9).

All major prostanoids including $\mathrm{PGD}_{2}, \mathrm{PGE}_{2}$, $\mathrm{PGF}_{2 \alpha}, \mathrm{PGI}_{2}$, and thromboxane $\mathrm{A}_{2}$ are synthesized in the kidney (36). Both $\mathrm{PGE}_{2}$ and $\mathrm{PGI}_{2}$ are important in renal function (37). $\mathrm{PGE}_{2}$ which is located in nephrons, the renal medullary interstitial cells and the collecting tubules, is a vasodilator and plays a major role in excretion of salt and water by the kidney. $\mathrm{PGE}_{2}$ binds to a form of G-proteincoupled receptor known as the prostaglandin-E (EP) receptor (38). Four forms of EP receptors have been identified, $\mathrm{EP}_{1-4}$ (23). $\mathrm{PGI}_{2}$ exerts its effect by binding to EP receptor and functions as a vasodilator in the kidney (36).

Any change in the renal function may influence CV system, hence, NSAIDs effect on the former may, in part, explain the complications seen in the latter (83) (84).

It is impossible to rank NSAIDs based on their renal side effect because comparative data are scarce if not nonexistent. Nevertheless, no NSAID can be assumed to be free of renal failure, at least, the acute type. It is important to emphasize that other analgesics such as acetaminophen are also associated with renal failure (4).

\subsubsection{Glomerular Filtration}

Glomerular filtration rate (GFR) is a reflection of damages to the renal system. Accordingly, both ARF and CRF secondary to NSAIDs are associated 
with reductions in GFR. For example, a lower value of GFR in the infants treated with ibuprofen for patent ductus arteriosus has been observed. The effect of ibuprofen is contributed to an induction of preglomerular arteriole vasoconstriction. (85).

Blann et al. (87) have reported an association between resistance to the ASA effect of the platelets and GFR in patients who were taking $75 \mathrm{mg} /$ day ASA. They noticed that ASA resistance was twice prevalent in patients with the greatest renal disease than those with the highest renal function. The authors speculated that either insufficient functioning of ASA contributed to dysfunction of the renal vasculature or there was an increase in the platelet turnover in the patients with renal disease.

Even after administration to the patients diagnosed with prostate cancer of high doses (400 mg twice daily for six months), celecoxib appears to have no significant effect on GFR as compared with pre-treatment value $(78.1 \pm 22 \mathrm{~mL} / \mathrm{min}$ versus $76 \pm 19 \mathrm{~mL} / \mathrm{min}$ ) (86). The work of Anavekar et al. revealed an inverse relationship between the value of GFR and risk of CV adverse events in elderly with prior myocardial infarction (MI) (84).

Knowledge of reduced GFR does not reveal the nature of renal failure. However, Wei et al (88) measured GFR of NSAIDs users and studied the outcome of this information on prescription habits of the caregivers. They noticed a significant drop in NSAIDs prescription in response to their action. On the other hand, analysis of the data collected as a part of a Veterans Health Administration safety database, has shown that, despite the availability of GFR values, patients with CRF continued to receive NSAIDs even in GFR ranges where these drugs are contraindicated (89).

\subsubsection{Acute Renal Failure}

ARF is a general term used to describe a rapid and sustained abruption of the renal function causing accumulation of waste products (e.g., urea, creatinine) (90). This side effect is typically dose and duration-dependent and reversible. Physical examination, laboratory data (e.g., an increase in serum creatinine), ultrasonographic and radiological tests can be utilized to diagnose ARF (67).

The use of NSAIDs can cause ARF by inhibiting production of $\mathrm{PGs}$ and consequently reducing the blood flow to the kidneys (67) and/or induction of interstitial nephritis (82). It is unlikely that the patient with normal renal function develop ARF secondary to taking NSAIDs (91) but those with a history of hypertension, heart failure, or diabetes have higher chance of developing these complications (92). ARF has been observed in a decompensated elderly patient on $25 \mathrm{mg}$ /day diclofenac for 3 years (93). Concomitant administration of aminoglycosides, angiotensinconverting enzyme inhibitors, angiotensin receptor blockers and diuretics increase the risk of developing ARF (91). A study of the French Pharmacovigilance database has revealed that one of the most frequently reported drug interaction is between angiotensin receptor blockers or diuretics and NSAIDs that results in ARF (94). This suggests that this potentially serious drug interaction is often ignored.

NSAIDs-induced ARF is widely reported in the published literature. For example, in a study evaluating preventive effect of naproxen against atrial fibrillation after coronary artery bypass graft (naproxen, $275 \mathrm{mg}$ twice daily for seven days, $\mathrm{n}=$ 82 vs placebo, $n=79$ ), naproxen caused higher incidence of ARF as compared with placebo (7.3\% vs. $1.3 \%, p=0.06)(95)$. In another study, ibuprofen induced ARF in $15 \%$ of infants treated for patent ductus arteriosus. Ibuprofen treated infant also demonstrated lower excretion of $\mathrm{PGE}_{2}$ in the urine compared to control group ( $\mathrm{P}<0.001)$ (36). Recently, a case of ARF induced by nimesulide in a 6-year old boy has been reported (96). The patient was presented with fever, vomiting and anuria with elevated serum potassium, BUN, and creatinine. Several days after discontinuation of nimesulide the values retuned to healthy values.

\subsubsection{Renal Papillary Necrosis}

Renal papillary necrosis is a destruction of some parts or all renal papillae (RPN) (4). NSAIDs may induce RPN by abruption of the blood flow to papillae and intensifying hypoxia present in papillae. Some cases of RPN have also been reported for several traditional NSAIDs and celecoxib. For example, a case of RPN induced by ibuprofen is reported by Broadis and coinvestigators. The patient (a 2-year old boy) who received ibuprofen for fever was presented with nausea and vomiting and high levels of creatinine and urea in the blood. Papillary necrosis was controlled after inserting double J stents (97). 


\subsubsection{Nephrotic Syndrome with Acute Interstitial Nephritis}

Inflammation in the spaces between kidney tubules is the underlying mechanism of developing acute interstitial nephritis (AIN) (4). Hypersensitivity to drugs, sepsis, and glomerular diseases can cause AIN (91). The incidence of AIN is rare. It occurs days after exposure and is reversible. Nephrotic syndrome is presented with edema, oliguria, and foamy urine (4). Hematuria and proteinuria can be observed as well. Due to inhibition of cyclooxygenase, an increase in production of other arachidonic cascade products (e.g., leukotrienes) can be responsible for induction of nephrotic syndrome by NSAIDs. A case of nephrotic syndrome induced by meloxicam is reported in a patient who had previous history of the syndrome after receiving diclofenac (98). The similarity in structure of diclofenac and meloxicam was speculated to be behind the hypersensitivity. Administration of an NSAID with a chemical structure different from those used before did no cause the syndrome in this patient.

\subsubsection{Electrolyte and Fluid Retention}

Sodium retention that occurs in $25 \%$ of patients exposed to NSAIDs (99) causes edema and weight gain (100). NSAID-induced sodium retention may be the result of increases in the expression of the $\mathrm{Na}-\mathrm{K}-2 \mathrm{Cl}$ co-transporter (101) which plays a role in excretion of sodium and maintaining the GFR (81). All NSAIDs have been reported to cause peripheral edema $(102,103)$. It has been suggested that the acute sodium retention by NSAIDs in healthy elderly subjects is mediated by the inhibition of COX-2, whereas, depression of GFR is due to inhibition of COX-1 $(102,103)$.

A significant number of studies have discussed the effect of both non-selective NSAIDs and COXIBs on sodium balance (4). For example, in a study of 12 children with monosymptomatic nocturnal enuresis and nocturnal polyuria and 11 controls, a single dose of indomethacin was given to both groups under standardized fluid and sodium intake (104). Compared to the baseline values, indomethacin caused significant decreases in the nocturnal sodium, urea and osmotic excretion in both groups. These were accompanied by reduced $\mathrm{PGE}_{2}$ excretion from $0.13 \pm 0.01$ to $0.06 \pm 0.01$ $\mathrm{ng} / \mathrm{kg} / \mathrm{h}$. Hence, the effect of indomethacin on sodium excretion was explained by inhibition of PGs. Similarly, Balas et al. reported a case of periorbital edema induced by both ibuprofen and naproxen used on separate occasions (105).

In contrast, in another study, the \% fractional sodium excretion was not affected by celecoxib (106). The study consisted of 12 normotensive subjects taking placebo or celecoxib (200 mg per day). Each volunteer randomly completed two 17day low salt or high salt diets with a one-month wash-out period. The $\%$ fractional sodium excretion for the placebo group in low salt and high salt periods were $0.05 \pm 0.01$ and $1.02 \pm 0.06$, respectively. The corresponding values for celecoxib group were reported to be $0.06 \pm 0.03$ and $1.11 \pm 0.24$, respectively. The lack of a renal effect caused by celecoxib was offered as an explanation for the observed lack of a significant change in the plasma or urinary $\mathrm{PGE}_{2}$ after treatment with celecoxib.

In our lab, through a set of animal studies, we have observed that the electrolyte retention property of NSAIDs is not dependent upon their COX selectivity (31) but is influenced by their tendency to accumulate in the kidney tissues (32). Meloxicam and celecoxib have approximately the same degree of COX selectivity but only the latter causes electrolyte retention. Interestingly, relative to the plasma concentration, celecoxib demonstrates much more accumulation in the kidneys than meloxicam.

Hyperkalemia which may be secondary to potassium retention can be diagnosed with an initial serum potassium concentration of $\geq 6 \mathrm{mEq} / \mathrm{L}$ in outpatient setting or within the first $48 \mathrm{~h}$ of hospitalization (107). It is well known that aldosterone increases the potassium excretion. Since $\mathrm{PGI}_{2}$ stimulates the juxtaglomerular cells in the kidney to release renin (108) and consequently aldosterone (109), an inhibition of $\mathrm{PGI}_{2}$ production by NSAIDs may result in hyperkalemia (108).

Regardless of the COX-2 selectivity, NSAIDs have been associated with hyperkalemia $(110,111)$. However, the results of a retrospective study including 1985 patients indicates that those under therapy with COXIBs were in higher risk of hyperkalemia than those on non-selective NSAIDs (OR, 2.56; 95\% CI, 1.03-6.36) (112). They noticed no significant difference in electrocardiogram abnormality between the two groups. Unfortunately, the authors did not identify the 
tested NSAIDs as they pooled all data together.

In a nested case-control study, including 18,326 patients diagnosed with hyperkalemia and 355,106 controls, no difference has been observed among patients taking none, one or two NSAIDs together (107). Though, certain NSAIDs made patient more prone to development of hyperkalemia. In that study, the use of rofecoxib, celecoxib, diclofenac or indomethacin was associated with the highest risk of hyperkalemia. However, the incidence was not correlated with COX-2 selectivity.

In a retrospective study, Katekao et al. (113) divided a cohort of congestive heart failure patients into users and nonusers of NSAID. They found that the cause of the disease in the users group to be acute coronary syndrome contrary to the previous reports suggestive of salt and water retention. No significant difference was noticed between the two groups with regard to mortality.

\subsubsection{Chronic Renal Failure}

Chronic renal or kidney failure occurs when an assault, disease or toxins, damage the kidneys resulting in inadequate removal of fluids and wastes. Although rare, NSAIDs cause CRF secondary to interstitial nephritis or papillary necrosis. CRF can be an end-stage disease. The risk of CRF is increased in patients who have experienced ARF.

The literature on the NSAID-induced CRF is controversial (114). However, Nderiti et al. have recently published a systematic review evaluating the data available on the CRF caused by NSAIDs (115). Their inclusion criteria included NSAID use over 6 months, $\mathrm{n} \geq 50$, age $\geq 45$ and GFR $<15-59$ $\mathrm{mL} / \mathrm{min} / 1.73 \mathrm{~m}^{2}$. They used 7 reports that complied with their criteria from which 3 had data suitable for meta-analysis. They found that regular doses of NSAIDs did not significantly elevate the risk of CRF (pooled RR ratio, 0.96; 95\%CI, 0.86-1.07). High doses, however, significantly increased the risk of CRF (pooled RR, 1.26; 95\% CI, 1.06-1.50). They concluded that it was unnecessary to avoid low therapeutic doses of NSAIDs in patients with moderate to severe CRF but suggested the lowest effective dose of NSAIDs should be prescribed.

Based on retrospective studies, some authors (e.g., 116) have suggested that NSAIDs with long half-life may demonstrate a greater risk of CRF due to their sustained inhibition of PG. The argument against this suggestion is that at the steady-state conditions, i.e., under pseudo-equilibrium throughout the body, the presence of a given NSAID in the site of action, albeit low for a drug with short half-life, may be sufficient to inhibit intercellular PG depending on its intrinsic potency for the reaction. On the contrary, a drug with long half-life, e.g., meloxicam, may possess less tendency to accumulate in the kidney cells due to its physicochemical properties, hence, potentially causing less renal effect (32). Indeed, there is no experimental data to confirm the influence of halflife on CRF caused by NSAIDs.

It is evident that chronic use of any NSAID can cause CRF in some patients despite the data suggestive of safety if the population mean is considered (e.g., 115).

\subsubsection{Hypertension Caused by Electrolyte Retention}

It is generally believed that NSAIDs increase blood pressure, especially in hypertensive patients (117). They can increase blood pressure by several mechanisms including retention of salt and fluid (118-120).

In a meta-analysis of 114 clinical trials, Zhang et al. evaluated peripheral edema, hypertension, renal dysfunction, and arrhythmia in subjects who took rofecoxib, parecoxib, etoricoxib, valdecoxib/parecoxib, etoricoxib, or lumiracoxib as compared to controls. Rofecoxib demonstrated a significant risk (RR) for renal side effects and arrhythmia as compared with placebo with RR for peripheral edema, hypertension, renal dysfunction, and arrhythmia of 1.43 (95\% CI, 1.23-1.66), 1.55 (95\% CI, 1.29-1.85), 2.31 (95\% CI, 1.05-5.07) and 2.90 (95\% CI, 1.07-7.88), respectively. Rofecoxib's side effects intensified with the elevations of the dose and duration of the use. Other NSAIDs were not significantly associated with the risk although some trends were evident. Interestingly, as compared to controls, celecoxib was associated with a lower risk of hypertension (RR, $0.83 ; 95 \%$ CI, 0.71-0.97) and renal dysfunction (RR, 0.61; 95\% CI, 0.40-0.94) (121). They, therefore, concluded that there was no COX-2 class effect event. This is in agreement with the result of a study in the rat that reported lack of correlation between COX-2 selectivity and electrolyte retention (31). In contrast, another meta-analysis of 51 randomized clinical trials concluded that COXIBs 
induced hypertension more that the non-selective NSAIDs (122).

\subsubsection{Summary of NSAIDs Renal Effects}

The use of all NSAIDs has been associated with dose-dependent renal side effects with various etiologies. Many of the side effects are short-term and reversible upon NSAID withdrawal. Chronic use of NSAIDs, although relatively free of renal side effects in average patient, in some, particularly those with other risk factors and/or on other drugs such as diuretics and angiotensin inhibitors, may result in end-stage chronic renal disease. However, for the majority of patients, renal side effects of NSAIDs are rare particularly if they avoid high therapeutic doses.

\subsection{Cardiovascular and Cerebrovascular Effects of NSAIDs}

Historically, GI side effects of NSAIDs were the main limitation of their use. Since the emergence of COXIBs and the subsequent withdrawal of rofecoxib (29), however, the CV complications have been highlighted as another major stumbling block against the use of NSAIDs. Nevertheless, both $\mathrm{CV}$ and renal side effects have been associated with NSAIDs since their introduction. A confounding factor in identifying the latter side effects of NSAIDs has been the CV complications that have been known to be associated with the very disease that these drugs are indicated for; i.e., both the inflammatory conditions and NSAIDs may result in CV complications. Forman et al. (48) have suggested that the frequency of nonnarcotic analgesic use (including all NSAIDs and acetaminophen) is independently associated with a moderate increase in the risk of hypertension. This has been disputed by those who suggested that the authors had not considered, as a covariate, the underlying reason for the use of analgesics and antiinflammatory drugs (123, 124). Inflammatory conditions, such as arthritis, adversely influence the $\mathrm{CV}$ system so that patients with arthritis are afflicted with $\mathrm{CV}$ conditions to a significantly greater extent than the general population (125128). Furthermore a decrease in the pharmacological effect of some drugs, particularly those to treat $\mathrm{CV}$ complications, is also observed in inflammation. This adds another risk factor for increased $\mathrm{CV}$ outcomes in the patients under treatment with NSAIDs for their arthritis (129).

\subsubsection{Composite Cardiac Outcome; COXIBS vs Other NSAIDs}

Rofecoxib was introduced to the market shortly after the first COXIB, celecoxib. Although the superiority of these two drugs over other NSAIDs was only their presumed less GI side effects, the aggressive direct-to-public advertisement gave the impression of a greater efficacy in treating arthritis, or even a new approach to the treatment of the disease. Hence, in some regions, they quickly became the most prescribed NSAIDs. However, early clinical trials such as Vioxx Gastrointestinal Outcomes Research (VIGOR) comparing rofecoxib $50 \mathrm{mg} /$ day with naproxen $1000 \mathrm{mg} /$ day in $8076 \mathrm{RA}$ patients, with no ASA use revealed a 5 fold increase in CV risks for patients taking rofecoxib (130). Additionally, the Adenomatous Polyp Prevention on Vioxx (APPROVe) trial, comparing $25 \mathrm{mg} /$ day rofecoxib $(n=1287)$ dose with placebo $(n=1299)$ in 2586 colorectal adenoma patients after 18 months of treatment also reported a greater risk of MI infarctions and ischemic cerebrovascular, congestive heart failure, and cardiac failure events for rofecoxib (131). The COX-2 selectivity and/or the lack of sufficient COX-1 inhibitory effect were raised as the reason for the unfortunate observations since the focus of the earlier reports was rofecoxib which was known to be the most selective COX-2 inhibitor. However, in contrast, the Celecoxib Long Term Arthritis Safety Study (CLASS) that compared a relatively high dose of another selective COX-2 inhibitor, celecoxib (400 mg, twice daily) with ibuprofen $800 \mathrm{mg}$ (three times a day) and diclofenac $75 \mathrm{mg}$ (twice daily) in 8059 patients with $\mathrm{OA}$ and RA, detected no significant differences between the examined NSAIDs in the CV incidence irrespective of ASA use (49).

Another review, although sketchy, suggests no significant difference in $\mathrm{CV}$ outcomes when rofecoxib $12.5 \mathrm{mg} /$ day, nabumetone $1000 \mathrm{mg} /$ day were compared with placebo for 6 weeks in OA patients when low dose ASA were concomitantly used (132). Adding to the already existed confusion, the authors concluded that selective COX-2 inhibitors use without ASA was associated with higher $\mathrm{CV}$ risk as compared to the non-ASA users (132). This implied that the lack of sufficient COX-1 inhibitory effect of rofecoxib can be compensated, at least in part, by the addition of ASA. The CLASS study (49), where celecoxib was 
found to be relatively without CV side effects, ASA use was not found to influence $\mathrm{CV}$ or renal side effect of the drug of interest.

Moreover, Mukherjee el at., suggested that both celecoxib and rofecoxib may increase the $\mathrm{CV}$ risk (133). They speculated that the reason behind the different observations between VIGOR and CLASS studies may be the different comparators used in the trials; naproxen and ibuprofen, respectively. In VIGOR trial naproxen decreased the $\mathrm{CV}$ risk, increasing the relative risk of rofecoxib. In the CLASS trail, on the other hand, the comparator was ibuprofen or diclofenac with relatively high risk ratio rendering the difference between them and celecoxib insignificant. Other plausible reasons for the differences between the two outcomes include the shorter duration of exposure for the former $(132,134)$.

Similar studies have been done on other NSAIDs. A RCT consisting of 23,504 patients with $\mathrm{OA}$ or RA (Multinational Etoricoxib and Diclofenac Arthritis Long-term, MEDAL) compared the effects of etoricoxib vs diclofenac. Etoricoxib is another COXIB from Merck \& Co. currently approved in more than 70 countries including the European Union but not in the US and Canada, where the regulatory agencies have required additional safety and efficacy. This study suggests the hazard ratio for $\mathrm{CV}$ events for etoricoxib as compared to diclofenac to be 0.96 (95\% CI, 0.81- 1.15) indicating no difference between the two NSAIDs (135). This does not imply a safe CV profile for the drug but merely suggests no significant differences between etoricoxib and diclofenac. In the latter study, the concomitant use of low dose ASA yielded similar results.

Recently, McGettigan and Henry reviewed the published evidence regarding $\mathrm{CV}$ risk profiles of NSAIDs in high, medium and low income countries (6). The results showed that NSAIDs like rofecoxib, etoricoxib, and diclofenac had consistently higher $\mathrm{CV}$ risks (RRs) as compared to naproxen. It is important to note that diclofenac is listed as an essential drug in 74 countries and is still capturing a market share of $14.7-58.7 \%$ of total NSAIDs prescription (6). As compared to naproxen, meloxicam and indomethacin demonstrated a moderate elevation of RR while etodolac did not increase RR significantly. Celecoxib and ibuprofen have been reported to have elevated RR risk in high doses used for clinical trials, but not in low doses as mostly used in clinical practice (6).

In a cohort study of 107,092 Danish individuals with chronic heart failure, the hazards ratios for death were observed to be 1.31 (1.251.37) for ibuprofen, 2.08 (1.95-2.21) for diclofenac, $1.22(1.07-1.39)$ for naproxen, $1.70(1.58-1.82)$ for rofecoxib, 1.75 (1.63-1.88) for celecoxib, and 1.28 (1.21-1.35) for other NSAIDs (136). The authors noted a relationship between the dose of drug and the CV toxicity. The adverse events were explained by thromboembolic function of certain NSAIDs (based on their selectivity for COX-2), renal dysfunction and hypertension caused by NSAIDs, possible changes in myocardium due to COX-2 inhibition demonstrated in animal models, and/or preexisting physiological changes because of heart failure.

Overall, it appears that, based on the composite CV side effects, the notion of selective COX-2 inhibition as the reason behind the NSAIDs $\mathrm{CV}$ risk can be ruled out. However, it's certain that rofecoxib causes serious $\mathrm{CV}$ complications particularly if it is taken without low dose ASA. The CV effect of other NSAIDs are still controversial, hence, cannot be unequivocally ruled out.

\subsubsection{Effect of Duration of Treatment}

There is no convincing evidence that a brief exposure to NSAIDs (e.g., used for relief of postsurgery pain) elevates CV risk. Indeed, a few days treatment with meloxicam, ketorolac or celecoxib are suggested to be free of increased risk of MI (137) or heart failure (138). Liu et al. (137) found no association of perioperative use of NSAIDs and postoperative MI infarction after total joint replacement.

Moreover, Mukherjee el at., have suggested another plausible reason for the differences seen between celecoxib (CLASS) and rofecoxib (VIGOR) with regard to their CV risks, the shorter duration of exposure to the former COXIB (133). A subsequent study reported that the risk of atrial fibrillation was higher among the patients who took NSAIDs for longer than one year (139). This is while another report suggested a greater risk of arterial fibrillation in the new users of non-selective NSAIDs, but not for COXIB (140). Similarly, a population based case-control study suggests a high 
risk of arterial fibrillation for new users of NSAIDs regardless of their COX selectivity (141). Moreover, a small increase in MI has been reported for ibuprofen only when new users were considered in statistical analysis (142).

Based on the forgoing discussion, the effect of duration of NSAIDs use is unclear. There may be a tolerance developed by continued use of some NSAID resulting in a relatively lower CV risk over time. Whether the early CV side effects and those following long time use manifest themselves through different mechanisms remains to be addressed.

\subsubsection{Dose-Dependency of CV Side Effects}

In a cohort study of patients with chronic heart failure, the hazards ratios for $\mathrm{CV}$ toxicity increased by NSAIDs use regardless of COX selectivity in a dose-dependent fashion (136). Another report (143) that has received criticisms (144-146) suggests ibuprofen increases the risk of CV toxicity at high doses due, presumably, to the lack of antithrombotic effect of high doses. Low doses of ibuprofen may even have cardioprotective effects as suggested by Fosbol et al. (147). The protective effect of ibuprofen in low doses $(\leq 1,200 \mathrm{mg} /$ day; $\mathrm{RR}, 0.78 ; 95 \% \mathrm{CI}, 0.73-0.084$ ) is stated to be due, perhaps, to the antithrombotic or ASA-like effect of the compound (147). This reflects the importance of considering the dose in these types of studies. While the overall use of ibuprofen is neutral, the low doses are protective and high doses $(\geq 1,200$ $\mathrm{mg}$ /day) slightly but significantly increase the risk ratio. Naproxen also appears to be cardioprotective in low doses but neutral in high doses (147). Likewise, higher doses of diclofenac, celecoxib, and rofecoxib were correlated with higher risk of MI or death (143).

According to a more recent review, celecoxib and ibuprofen have elevated CV risks in high doses used for clinical trials, but not in low doses as mostly used in clinical practice (148). Another study (142) suggests that the use of NSAIDs including rofecoxib is associated with only a small elevation of acute MI risk. The magnitude of the $\mathrm{CV}$ risk, however, increased by higher doses for all tested NSAIDs except for diclofenac. In the elderly, it appears that the first time MI risk increases with the use of rofecoxib in a dose-dependent manner (149).

There seems to be consensus among the researchers that, indeed, higher dose are associated with greater risks of $\mathrm{CV}$ complications. This is a good news since the safer dose ranges of NSAIDs are still in the therapeutic range. However, it is important to note that patients often increase their prescribed doses based on their conditions with or without their caregiver's recommendation. The dose dependency of drugs such as ibuprofen ranging from cardioprotective to cardiotoxic also has important therapeutic value particularly for patients in less risk of GI complications. Similarly, the possible cardioprotective effect of low dose naproxen is worthy of serious consideration.

\subsubsection{Risk of Cardiac Death, All-Cause Mortality}

In the elderly, the issue of death due to NSAIDs use is controversial. In a nested case-control study conducted on the Australian veterans, Mangoni el at., reported a reduction in all-cause mortality reported for all NSAIDs regardless of their COX selectivity (OR $0.87,95 \%$ CI $0.85,0.90$ ). The risk of death was also inversely associated with the number of prescription supplies (138). On the other hand, in a ten-year cohort study, Kerr et al. measured all-cause mortality outcome in the users of NSAIDs also in the Australian veteran population. They reported an elevated risk of death due to $\mathrm{CV}$ complications in the users of NSAIDs regardless of their COX selectivity (150). As compared to the non-NSAID treatments, they noticed the highest hazard ratio for all non-selective NSAIDs $(1.76 ; 95 \%$ CI, 1.59 - 1.94) followed by rofecoxib (1.58; 95\% CL, 1.39 - 1.79), meloxicam (1.49; 95\% CI, 1.25 - 1.78), diclofenac (1.44; 95\% CI, 1.28 - 1.62) and celecoxib (1.39; 1.25 - 1.55). The authors cast doubt on the meloxicam data due to "insufficient longitudinal" observation and suggested continuing monitoring. The substantially smaller number of patients on the drug may be another explanation; for the COXIBs, population size was the highest for celecoxib and smallest for meloxicam. It is unclear if the longer duration of follow up used for the non-selective NSAIDs (133 days) as compared with the COXIBs (60 days) had influenced the greater risk for the former. Kerr et al. attributed the difference between their data and the earlier ones to a wider definition of NSAID exposure and a case-control design assessing risk using a conditional logistic regression approach used by Mangoni et al. Individuals were eligible for 
inclusion by Kerr et al. if they had been on the same NSAID for 60-133 days depending on the drug; a gap in supply of the study drug greater than 30 days excluded the patient. On the other hand, Mangoni et al. (138) who stratified their cohort according to the extent of use, allowed gaps; e.g., used 30 days-2 years; used once or twice within the last 30 days, used more than twice within the last 30 days.

Fosbol et al. estimated the risk of $\mathrm{CV}$ death associated with NSAIDs as composite event of coronary death, MI and stroke in a Danish Nationwide cohort that consisted of 4,416,807 individuals aged 10 years or older. The use of diclofenac (OR 1.91, 95\% CI 1.62-2.42) and rofecoxib (OR 1.66, 95\%CI 1.06-2.59) was associated with higher risk of $\mathrm{CV}$ death. There was a trend towards higher stroke risk with ibuprofen use (OR 1.29, 95\% CI 1.02-1.63) but naproxen was void of any risk (OR $0.84 ; 95 \% \mathrm{CI}, 0.50$ to 1.42 ) (143). In addition, ibuprofen increased the risk of CV toxicity at high doses. According to the authors, this could be due to the lack of antithrombotic effect at high doses. Higher doses of diclofenac, celecoxib, and rofecoxib were correlated with higher risk of death/MI. Of note, the study has received several criticisms for its methodology and conclusion (144-146).

The possibility of death caused by NSAIDs in young and apparently healthy subject has been studied by Fosbol et al. (147) who presented the most striking data on the harmful effect of short periods (9-34 days) and often low doses of NSAIDs in a large Danish population of 10 years and older individuals with median age of around 40 years. They studied death and MI within a nine-year follow-up period. The authors reported a dosedependent increase in the risk ratios (RR; 95\% confidence limits) as compared to non-NSAID users with a RR of $1.01(0.96-1.07)$ for ibuprofen, 1.63 (1.52-1.76) for diclofenac, $0.97(0.83-1.12)$ for naproxen, 2.13 (1.89-2.41) for rofecoxib, and 2.01 (1.78-2.27) for celecoxib. They found no significant difference in risk associated with the first few days of treatment compared with the rest of the treatment interval. Most of the events happened later than 10 days into the treatment period. In the population of one million NSAIDs users studied by the Fosbol et al., 63 excess deaths per year were reported. The authors concluded that the absolute risk of NSAID-related death and CV events is, however, low, thus, in these types of studies, a high number of patients is needed to assess any statistical significance. However, they admitted that their study was only observational by nature since the reason for NSAIDs prescriptions were not available. It is interesting that the authors who had adjusted their data for various covariates did not do so for the underlying reason for taking NSAIDs. Ignoring the effect of the inflammatory conditions on the CV system may introduce great errors in the interpretation of data (125).

Even more interesting than Fosbol et al.'s observation (147) is the report of Goodson et al. that, through a population based study consisting of 923 inflammatory polyarthritis patients from the UK Norflok Arthritis Register (NOAR), suggest no increase in the risk of death for the users of NSAIDs and instead an inverse association between all-cause mortality and CV mortality. They speculate that the use of NSAIDs in patients with chronic inflammation may influence the eicosanoid pathway toward a net beneficial effect on the CV system (151). In support of Goodson et al. data that dealt with patients with chronic inflammation (151), a very recent report (152) suggests a lower overall NSAID related CV risk in RA patients (RR, 1.22; 95\% CI 1.09 to 1.37 ) as compared with non-RA subjects (RR, $1.51 ; 95 \%$ CI 1.36 to $1.66, \mathrm{p}<0.01)$. They also concluded that among 9 NSAIDs tested only rofecoxib and diclofenac were associated with increased CV risk (152). Similarly, in a cohort of colorectal cancer patients, Zell et al. reported a decrease in mortality with the prolonged use of NSAIDs (153). Apparently, the difference in the finding of these studies can be explained by difference in study design and lack of control on exposure and shorter duration.

The heterogeneity in patient population and study design and small number of events make any unequivocal conclusion regarding the risk of death and NSAIDs use impossible. In many of these studies, particularly those with historic data, the influence of chronic inflammation which NSAIDs are intended for, is ignored. This is important since inflammation is by itself a risk factor of $\mathrm{CV}$ complications and death; NSAIDs control inflammation, thereby, theoretically should reduce the cause for increase $\mathrm{CV}$ risk as some clinical observations suggest (95). It is generally believed that certainly rofecoxib and probably diclofenac use are associated with $\mathrm{CV}$ events. There is no consensus, however, to extrapolate the observation 
made on the above NSAIDs to the entire class of compounds.

\subsubsection{Risk of Myocardial Infarction}

Amongst the CV conditions associated with NSAIDs, MI is the most studied, due, perhaps, to being more lethal and most common. Most studies have reported the risk associated with all NSAIDs with varying intensity, dose and duration (148). The mechanism of the CV effect of NSAIDs is unclear but, at electrophysiology level, Grimaldi-Bensouda et al. have found that the MI risk modification associated with NSAID is limited to non-ST elevation (154).

Initially, only the COXIBs were highlighted as the NSAIDs associated with an increased risk of MI, until, Kaiser Permanente trials (155) raised the questions over CV risk for all NSAIDs. Subsequent reports $(142,156,157)$ challenged the previous belief. For example, retrospective cohort studies suggest an increased risk for CV outcome even with non-selective NSAIDs such as diclofenac and ibuprofen $(142,156,157)$. Others also reported no cardioprotective effects for any tested NSAID contrary to what previously noticed for naproxen and indomethacin (158-160).

A recent meta-analysis of the major randomized controlled trials on the effect of NSAIDS has concluded that, except for naproxen, NSAIDs used commonly in clinical practice are associated with increased risk of acute MI at high doses or in the patients previously diagnosed with coronary heart disease. For diclofenac and rofecoxib, the risk is elevated for both low and high doses (161). This is in agreement with another previously reported meta-analysis that concluded that although uncertainty remains, a little evidence exists to suggest if any of the investigated drugs are safe in CV terms but apparently naproxen seemed least harmful (162).

In a case control study, Solomon et al .compared the risk of MI associated with celecoxib and rofecoxib in a group of patients who received no NSAIDs using the Medicare database. The use of rofecoxib was associated with higher risk (RR, 1.24; 95\% CI, 1.05-1.46) as compared with that of celecoxib and no NSAID (163).

A 2-year follow-up of individuals age 18 or older revealed no increased risk of MI with nonselective NSAIDs. The use of rofecoxib was associated with higher incidents of acute MI (RR,
3.30; 95\% CI, 1.41 - 7.68; $\mathrm{p}=0.01)$. Although celecoxib did not increase the risk of acute MI (RR, 1.44; 95\% CI, $0.57-3.69 ; \mathrm{p}=0.44)$, it significantly elevated the risk of stroke (RR, 2.43; 95\% CI, 1.05 $5.58 ; \mathrm{p}=0.04)$. The use of all NSAIDs caused hemorrhages, however, it was more severe in celecoxib and rofecoxib groups (164).

Varas-Lorenzo et al. conducted a cohort study including 365,658 subjects aged 40-85 in Canada (142). The use of celecoxib, rofecoxib, diclofenac, naproxen, ibuprofen, or indomethacin was associated with a small elevation of acute MI risk (5.1/1000 person/year). The magnitude of the risk increased for ibuprofen only when new users were considered in the statistical analysis. Except for diclofenac, the high doses of other drugs were associated with higher risk of $\mathrm{CV}$ toxicity.

A cohort study of Australian veterans and dependents $(n=85,807$ and age $=75-79$ years $)$ examined the number of deaths in celecoxib, rofecoxib, meloxicam, diclofenac, and nonselective NSAIDs groups compared to mortality in a reference group (150). Adjusted hazard ratios for celecoxib, diclofenac, meloxicam, rofecoxib, and non-selective NSAIDs were reported to be 1.39 (1.25-1.55), 1.44 (1.28-1.62), 1.49 (1.25-1.78), 1.58 (1.39-1.79), and 1.76 (1.59 - 1.94), respectively. Accordingly, there was a small increase in CV toxicity for both selective and non-selective NSAIDs.

It has been intuitively believed that the CV risk associated with NSAIDs is greater with their long term use (18 months) as it has been observed in the APPROVe trial (131) until recently, when a cohort study from Europe reported that even a short term use of NSAIDs by patients with a history of MI increases the risk of death and MI (165). However, the study has received much criticism on its design and the analysis approach.

The history of previous MI on the CV risk of NSAIDs has been investigated. A group of researchers have reported (149), in the elderly currently on rofecoxib and with no history of MI, evidence of an increased risk of acute MI which was further elevated at higher doses. These authors detected no increased risk with celecoxib or other NSAIDs. Interestingly, according to these investigators, ASA use reduces the risk associated with low-dose but not high-dose rofecoxib. Later, the same group (166) noticed that patients with and without previous MI were at increased risk of MI 
with a non-significant trend for a greater risk among those with a previous event (RR, $1.23 ; 95 \% \mathrm{CI}$, $1.05-1.45$ vs. RR, $1.59 ; 95 \%$ CI, $1.15-2.18 ; \mathrm{p}=$ $0.14)$. They also reported that, celecoxib was associated with a significant increased risk only in people with previous MI (RR 1.40; 95\% CI, 1.06 1.84 vs. RR, 1.03: 95\% CI, $0.88-1.20 ; p=0.04)$.

Likewise, Lonas et al. who conducted an observational study of 3,293 patients taking NSAIDs for OA (the LOGICA study) observed a high risk of CV (167). A high risk of CV toxicity was noticeable among patients with previous MI after short and long term NSAID therapy (165).

A dose-related death due or re-infarction has been reported in the Danish population who used NSAIDs (168). The authors concluded that all doses of celecoxib and rofecoxib but only high doses of non-selective NSAIDs dosages increase mortality in patients with previous MI. They suggested that these drugs should, therefore, be used with particular caution in these patients. This is when another study reports that there is "no difference between acute MI occurrences in the elderly patients taking rofecoxib or celecoxib at recommended doses for chronic indications versus those taking ibuprofen/diclofenac. However, the risk of acute MI was higher among patients using higher doses of rofecoxib (>25 mg/day) compared to patients using higher doses of celecoxib (>200 $\mathrm{mg}$ /day)" (169).

Warner et al. (170) compared etodolac with naproxen in a historical cohort analysis consisting of 38,258 US veterans. They also included celecoxib and rofecoxib as positive controls. The outcome was very interesting since it may rejuvenate interest in etodolac, an old drug with a favorable COX-2/COX-1 inhibitory property (Table 2 ), and a general belief of positive safety profile. As compared to naproxen, the increased risk of acute MI was not significant for etodolac (OR, 1.32; $p=$ 0.27 ) but was so for celecoxib and rofecoxib. The authors' conclusion on the safety of etodolac that confirms another report (6), of course, is on the assumption that naproxen does not increase the risk of MI. However, to back their claim, they demonstrated that neither naproxen nor etodolac were independent predictors of MI.

It is likely that some NSAIDs may increase the risk of MI particularly in high doses and with more certainty in patients with history of previous attack. Rofecoxib appears the most toxic of all tested NSAIDs while naproxen and etodolac may be the safest.

\subsubsection{Risk of Cardiogenic Stroke}

The effect of NSAIDs on the risk of stroke has been evaluated by several investigators. A retrospective cohort study of subjects aged 50 to 84 years old showed an increase in the risk of stroke among those who took rofecoxib or valdecoxib but not in those on several non-selective NSAIDs (diclofenac, ibuprofen, naproxen, and indomethacin) (160). In contrast, another retrospective cohort study of 162,065 Australian veterans found that, except for ibuprofen, both non-selective (naproxen, indomethacin, piroxicam, meloxicam, and diclofenac) and COXIBs (celecoxib and rofecoxib) increased the risk of stroke (171). Another retrospective nested case control study carried out on the Australian veteran population suggests no increased risk of stroke in non-selective NSAIDs users (138). In a meta-analysis of 31 trails comparing NSAIDs with placebo, ibuprofen was associated with the highest risk of stroke (3.36; 95\% CI, 1.00-11.6) followed by diclofenac (2.86; 95\% CI, 1.09-8.36), etoricoxib (4.07; 95\% CI, 1.23$15.7)$ and diclofenac high dose $(3.98 ; 95 \% \mathrm{CI}$, 1.48-12.7) (162) .Yet in another study pooled RR of stroke was higher for rofecoxib $(1.64 ; 95 \% \mathrm{CI}$, 1.15-2.33) and diclofenac (1.27; 95\% CI, 1.08-1.48) but not for naproxen, celecoxib, ibuprofen (172). Another study suggests a 1.88 times increased risk of stroke (95\% CI, 1.70-2.08) in general population using NSAIDs (171).

No clear conclusion can be made regarding the possibility of an increased risk of stroke in the users of NSAIDs as the literature, that is all based on historical evaluations, is highly controversial. Heterogeneity on the tested population and differences in the methodologies may explain the controversy.

\subsubsection{Risk of Thromboembolic Event}

The outcome of the most of the clinical trials suggests a positive association between the use of NSAIDs and increased thromboembolic events regardless of their COX-2 selectivity $(173,174)$. The mechanism behind this effect of NSAIDs which has been known for decades is their ability to interfere with the prostacyclin pathway. For 
example, Ross et al. who conducted a placebo control meta-analysis of rofecoxib clinical trials consisting of 2586 patients have suggested a higher risk of thromboembolic event in the users of rofecoxib (RR, 2.18; 95\% CI, 0.93-5.81) (175). However, meloxicam is reported to have a favorable thromboembolic profile (176) over other NSAIDs including celecoxib (177).

Layton et al. have compared the thromboembolic risk associated with the use of celecoxib (178) and rofecoxib (178) with meloxicam using retrospective data. They noticed a small increase in the rate of cerebrovascular thromboembolic events in users of celecoxib compared to meloxicam but not in the rate of $\mathrm{CV}$ thromboembolic or peripheral venous thrombotic events (178). They also reported a small relative increase in the rate of cerebrovascular thromboembolic events and a relative reduction in peripheral venous thrombotic events in the users of rofecoxib as compared with meloxicam. They, however, noticed no difference in the incidence of $\mathrm{CV}$ thromboembolic events between the users of rofecoxib and meloxicam (178).

Most NSAIDs disrupt the thrombotic state by creating an imbalance between the $\mathrm{TXA}_{2}$ and antithrombotic prostaglandins. This side effect is expected regardless of COX-2 selectivity. In a recent meta-analysis, Kearney et al. (179) have reviewed the clinical trials for vascular events resulted from the use of NSAIDs. They reported a $42 \%$ relative increase in serious vascular events in the COXIB user as compared with placebo. The risk was consistent among the tested NSAIDs.

\subsubsection{Risk of Atrial Fibrillation}

Multiple studies indicate an elevated risk of atrial fibrillation (AF) associated with the use of NSAIDs $(95,140,141)$. A recent well-done review has shed light onto many aspects of this issue (44). We, therefore, will highlight only a few key studies.

A nested case-control study of patients aged 40-89 years revealed an association between current use of NSAIDs and the development of AF (RR, 1.44; 95\% CI, 1.08-1.91) (139). The risk was higher among the patients who took NSAIDs for more than one year. Similarly, a larger cohort study consisting of 7,280 Taiwanese patients diagnosed with AF and 72,800 controls evaluated the exposure of patients to non-selective (ketorolac, ketoprofen, ibuprofen, etodolac, diclofenac, indomethacin, sulindac, piroxicam, meloxicam, naproxen, fenoprofen, flurbiprofen, tenoxicam, mefenamic acid, meclofenamic acid, flufenamic acid and tolfenamic acid) or COXIBs (celecoxib and rofecoxib) and the risk of AF (140). Investigators reported a high risk of $\mathrm{AF}$ for new users of non-selective but not for patients who took COXIBs. It is worthy of noting that the authors included etodolac among the nonselective NSAIDs.

In contrast, a population based case-control study suggested an increased risk of $\mathrm{AF}$ for new users of NSAIDs regardless of their COX selectivity (141). The study included 32,602 patients diagnosed with $\mathrm{AF}$ and 325,918 matching controls.

Since there may be a relationship between inflammation and AF, Hobach et al. (95) hypothesized that the use of the antiinflammatory naproxen in post-operative patients may reduce the incidence of AF. They, therefore, carried out a randomized, double-blind, placebo-controlled study in 161 Brazilian patients undergone coronary artery bypass graft. They were administered $275 \mathrm{mg}$ oral doses of naproxen or placebo every $12 \mathrm{~h}$ for $120 \mathrm{~h}$ commencing immediately after surgery. The use of naproxen failed to reduce the incidence of AF but decreased its duration in a limited sample of the patients. The outcome of this study is not unequivocal since, as the authors pointed out, the data were analyzed with limited statistical power. In addition, the inflammatory states of the patients were not tested to see if the intervention had controlled the expression of inflammatory mediators. Moreover, the patients in both groups were already on drugs with known antiinflammatory effects such as HMG-CoA reductase inhibitors $(180,181)$ and ACE inhibitors (182-184), hence, the plausible additional effect of naproxen could have been masked.

It appears that NSAIDs increase the incidence of AF despite their antiinflammatory properties. However, more studies are needed to address the controversy in the published studies. The focus of the future investigations should be the effect of the dose, the duration of treatment and the history of CV complications on the NSAIDs therapy outcome.

\subsubsection{Risk of Elevated Blood Pressure and Hypertension}

The effect of NSAIDs on the kidneys and consequently their role on the excretion of 
electrolytes and water retention has been discussed above. The NSAIDs induced electrolyte imbalance, coupled with NSAIDs inhibitory effect on the production of vasodilator prostacyclin $\left(\mathrm{PGI}_{2}\right)(185)$, results in increased blood pressure, hypertension and consequently, CV complications. Several placebo control clinical trials have shown that NSAIDs regardless of their COX selectivity are associated with increased $\mathrm{CV}$ risk through such mechanisms. $\mathrm{Yu}$, et al. (186) have shown that a blockage of vascular COX-2 results in a lower PGI$\mathrm{M}$ in the urine predisposing the animal to both hypertension and thrombosis. Moreover, blockade of vascular COX-2 is linked to a lower endothelial NO synthase suppression of $\mathrm{PGI}_{2}$ which is likely to augment the already compromised blood pressure homeostasis. Another study has suggested the hardening of arteries as the mechanism for increased peripheral resistance caused by NSAIDs that results in hypertension and serious CV event (186).

Epidemiological studies are generally in agreement with the above mentioned reports, albeit, there is a controversy on the ranking of these drugs to increase blood pressure. For example, as compared with acetaminophen, first prescription of NSAIDs moderately increases systolic blood pressure by $2 \mathrm{~mm} \mathrm{Hg}$ in hypertensive patients with a great data variability (95\% CI, 0.7 - 3.3). However, NSAIDs fail to influence blood pressure in patients who are concurrently taking diuretics or those who use combinations of two or more antihypertensive medications. Compared to naproxen, ibuprofen is associated with a $2.5 \mathrm{mmHg}$ increased systolic blood pressure (95\% CI, 0.5 4.6). In addition, ibuprofen is associated with a clinically important increased systolic blood pressure with a risk factor of 1.47 (95\% CI, 1.09 1.96). Compared to ibuprofen or naproxen, celecoxib is not associated with a clinically important increase in systolic blood pressure (187).

Krum et al. reported that etoricoxib is associated with higher systolic $(p<0.0001)$ and diastolic blood pressure ( $p<0.0001$ to $p=0.0015$ ) compared to diclofenac (188). Likewise, naproxen is also reported to cause elevation of blood pressure in a randomised control trial of 916 patients (189). Others have concluded that all selective and nonselective NSAIDs have the ability to disrupt the blood pressure homeostasis with varying degree (120).
Elliott (190) addresses the fact that methodology in recording and reporting blood pressure data may result in different interpretations but agrees that NSAIDs do increase blood pressure. The reviewer shows a significant correlation between blood pressures and $\mathrm{CV}$ events and, for more definite and reliable conclusions, he looks forward to the finding of an ongoing trial, the 'Prospective Randomized Evaluation of Celecoxib Integrated Safety versus Ibuprofen or Naproxen' (PRECISION).

In many studies the possibility of a combined or linking renal and $\mathrm{CV}$ side effects, i.e., a cardiorenal comorbidity, is ignored. Whelton et al. (191) conducted a 6-week, randomized, parallelgroup, double-blind trial comparing celecoxib with rofecoxib in 810 OA patients. They noticed edema in the users of rofecoxib approximately twice as many as in the celecoxib-treated patients $(9.5 \%$ vs. $4.9 \% ; p, 0.014)$. Increased systolic blood pressure was observed in $17 \%$ of the rofecoxib and $11 \%$ of the celecoxib $(p, 0.032)$ users. There was no significant difference between the two groups in elevation of diastolic blood pressure (increased in $2.3 \%$ of rofecoxib- compared with $1.5 \%$ of celecoxib-treated patients, $p, 0.44)$. After 6 weeks of treatment, the change from baseline in systolic blood pressure $(\mathrm{mm} \mathrm{Hg})$ was +2.6 for rofecoxib and -0.5 for celecoxib $(P, 0.007)$. Another recent study by Hegazy et al. (83) has reported a safer cardiorenal profile for celecoxib than for ibuprofen in elderly population with OA and RA manifested as lower incidences of hypertension and edema for the latter drug.

In general, blood pressure of patients on NSAIDs needs to be monitored as the possibility of a few $\mathrm{mm} \mathrm{Hg}$ increases by this entire class of drugs exists, if not in the population mean, in some individual patients.

\section{CONCLUSION}

NSAIDs are used by a substantial number of people diagnosed with arthritis and other related diseases to reduce inflammation and pain associated with these conditions (4). They are potent drugs and, as such, are expected to be associated with various side effects that include GI, renal and CV implications. These side effects may be relatively rare but can be serious. Although some NSAIDs appear to be more toxic than others, their ranking 
merely based on their mechanism of action, e.g., selectivity in COX-2 inhibitory, seems futile since rofecoxib with a very high COX-2 selectivity appears to be as harmful to the GI tract as the conventional competitors (77).

Overall, considering the increased incident of $\mathrm{CV}$ and renal complications associated with inflammatory conditions (125), even a slight risk of aggravating these adverse effects may result in serious outcomes particularly in high risk patients. The damage to the kidney includes a reduction in GFR and tubular injury. CV events such as MI and/or death associated with several NSAIDs are reported by many investigators. In addition, cerebrovascular events and ARF have been linked to use of NSAIDs.

The reports covering the side effects of NSAIDs consist of a limited number of clinical trials but many retrospective epidemiological studies. Often, they do not agree with one another but the consensus is that NSAIDs do cause serious side effects albeit with a low prevalence. Some studies are of low value as 1) they pool data collected for various drugs, hence as such, the mean data may mask properties of a given drug. 2) They generalize observations based on data generated using one or few drugs. It has become clear that the observation made on certain drugs, e.g., rofecoxib, cannot be extrapolated to all selective COX-2 inhibitors, e.g., celecoxib, meloxicam or etodolac. This hold true for the conventional NSAIDs as well. 3) No information on the dose and formulation is included. The side effects of NSAIDs are dosedependent so that the information obtained based on data collected using high doses do not necessarily reflect the properties of low doses. In addition, modified release formulations have their own specific side effect profile that may not be necessarily similar to the immediate release forms. 4) Many clinical and epidemiological studies suffer from heterogeneity in both patients and methodology, and some ignore the effect of the pathophysiological condition of the included patients.

Nevertheless, there are some NSAIDs that appear to be less toxic than others. They include naproxen and celecoxib $(143,176,192)$. Etodolac and meloxicam may also be included in the list although, due to scarcity of data, a clear conclusion cannot be made. Among the available NSAIDs, diclofenac seems to be associated with the highest
CV complication $(143,192)$ and, perhaps, should be avoided although it is found in the essential list of many countries.

Low therapeutic doses of NSAIDs appear to be safe to be used by patients who do not have renal and/or CV co-morbidities. Indeed, there is a possibility of cardio-protection for low doses of some NSAIDs such as ibuprofen and naproxen. Monitoring of patients particularly those with comorbidities is essential. Nevertheless, under any condition, the potential for causing GI damages, including those that are often ignored and occur in the lower parts of the tract, has to be considered regardless of the mechanism of action, dose, and pharmaceutical formulation of these NSAIDs. The use of GI protective drugs such as misoprostol along with NSAIDs by patients at risk of GI complications is advisable (201). The $\mathrm{pH}$ controlling drugs appear to be effective in protecting the upper GI but their beneficial effect on the lower GI is not proven. Enteric coated, including low dose ASA, and controlled-release NSAIDs are associated with side effects in the lower GI tract.

Many patients can benefit from non-NSAID analgesics such as acetaminophen and antiinflammatories such as glucosamine which have favorable safety profiles. Toxic doses of acetaminophen result in serious hepatic disorders but even high therapeutic doses of the drug are free of major side effects. The clinical benefit of glucosamine is controversial mainly due to the use of low quality products and under-dosing (193). Nevertheless, many patients are satisfied with the outcome of glucosamine therapy.

Topical NSAIDs are other alternative medications for some patients. Due to the lower systemic exposure, i.e., lower absorption into the systemic circulation, as compared to the oral doses, they are expected to cause less serious side effects. The possibility of skin rashes due to topical application of NSAIDs, however, should be kept in mind.

It is important to realize that many inferences made on the safety of drugs are based on the comparison of the means of two or more clinical or epidemiological observations. We, typically, conclude safety when the mean of the observation made in those using the drug is not significantly different from those on placebo. This, by no means, implies that no patient taking the drug will 
experience side effects. It is, therefore, of prime importance to consider individualizing the therapeutic plan and monitoring based on the condition of the patient.

\section{ANTICIPATED ADVANCES IN THE KNOWLEDGE OF THE FIELD}

There are many efforts ongoing to produce better antiinflammatory drugs and also to find ways to render antiinflammatory treatments safer and more efficacious. We include a few examples. To minimize the $\mathrm{CV}$ effects of selective COX-2 inhibitors, investigators have suggested targeting the $\mathrm{TXA}_{2}$ receptor to balance the undesired CV effects of NSAIDs (194)

Research and development activities, including clinical trials, are still ongoing on the very much anticipated nitric oxide donating NSAID. By the virtue of donating NO, these drugs are speculated to reduce the $\mathrm{CV}$ and GI side effect of NSAIDs (195).

Knights et al. have suggested that the in vitro data used to find selectivity of COX for NSAIDs is debatable and explanations for the $\mathrm{CV}$ toxicity based on an imbalance of COX-2-derived $\mathrm{PGI}_{2}$ and COX-1-derived thromboxane $\mathrm{A}_{2}$ cannot be plausible (196). They have recommended more standardized in vitro kinetics studies determining inhibitor constant and rate constant to define true selectivity of NSAIDs toward inhibition of COX. We add that the scope of the search for safe antiinflammatory drugs should be broadened to the molecular level and cover various receptors involved in the side effects and also to explore pharmacokinetic and drug delivery potentials. In addition, to predict various side effects of NSAIDs, identification of readily measured biomarkers is of therapeutic interest.

Pharmacogenetics appears to have a role in the CV complications of NSAIDs (197). St. Germaine et al. have associated the susceptibility to NSAIDs' CV complications to genetic polymorphism (198). They have identified the prostaglandin-endoperoxide synthase-1 and Creactive protein genes as the candidates for a possible gene-drug interaction influencing the acute coronary risk associated with NSAID use.

Two large scale clinical trials are ongoing, The Prospective Randomized Evaluation of Celecoxib Integrated Safety versus Ibuprofen Or
Naproxen (PRECISION) trial (199) and The Standard care versus Celecoxib Outcome Trial (SCOT) trial (200). They are expected to improve our understanding of the safety of NSAIDs.

\section{CONFLICT OF INTEREST}

Authors have no conflict of interest regarding the content of the article.

\section{REFERENCES}

1. Vane JR. The fight against rheumatism: from willow bark to COX-1 sparing drugs. J Physiol Pharmacol. 2000 Dec;51(4 Pt 1):573-86.

2. Roberts LJ, Morrow JD. Analgesic-Antipyretic and Antiinflammatory Agents and Drugs Employed in the Treatment of Gout. In: Hardman JG, Limbird LE, editors. Goodman \& Gilman's The Pharmacologic Basis of Therapeutics: McGRAWHILL; 2001.

3. Conaghan PG. A turbulent decade for NSAIDs: update on current concepts of classification, epidemiology, comparative efficacy, and toxicity. Rheumatol Inter. 2012 Jun; 32(6):1491-502.

4. Harirforoosh S, Jamali F. Renal adverse effects of non-steroidal anti-inflammatory drugs. Expert Opin Drug Saf. 2009;8(6):669-81.

5. Bleumink GS, Feenstra J, Sturkenboom MC, Stricker BH. Nonsteroidal anti-inflammatory drugs and heart failure. Drugs. 2003;63(6):525-34.

6. McGettigan P, Henry D. Use of non-steroidal antiinflammatory drugs that elevate cardiovascular risk: an examination of sales and essential medicines lists in low-, middle-, and high-income countries. PLoS medicine. $2013 \mathrm{Feb}$;10(2):e1001388.

7. Knights KM, Winner LK, Elliot DJ, Bowalgaha K, Miners JO. Aldosterone glucuronidation by human liver and kidney microsomes and recombinant UDPglucuronosyltransferases: inhibition by NSAIDs. Britj Clin Pharmacol. 2009 Sep;68(3):402-12.

8. Ritter JK. Roles of glucuronidation and UDPglucuronosyltransferases in xenobiotic bioactivation reactions. Chemico-biologl interac 2000 Dec 1;129(1-2):171-93.

9. Bennett WM, Henrich WL, Stoff JS. The renal effects of nonsteroidal anti-inflammatory drugs: summary and recommendations. Am J Kidney Dis. 1996 Jul;28(1 Suppl 1):S56-62.

10. Essex MN, Zhang RY, Berger MF, Upadhyay S, Park PW. Safety of celecoxib compared with placebo and non-selective NSAIDs: cumulative meta-analysis of 89 randomized controlled trials. Expert Opin Drug Safety. 2013 Jul;12(4):465-77.

11. Wagner W, Khanna P, Furst DE. Nonsteroidal Anti- 
Inflammatory Drugs, Disease-Modifying Antirheumatic Drugs, Nonopioid Analgesics, \& Drugs Used in Gout. In: Katzung BG, editor. Basic \& Clinical Pharmacology: McGraw-Hill; 2003.

12. Jordan S, White J. Non-steroidal anti-inflammatory drugs: clinical issues. NursStand. 2001;15(23):4552.

13. Warner TD, Giuliano F, Vojnovic I, Bukasa A, Mitchell JA, Vane JR. Nonsteroid drug selectivities for cyclo-oxygenase-1 rather than cyclo-oxygenase2 are associated with human gastrointestinal toxicity: a full in vitro analysis. ProcNatlAcadSci USA. 1999;96(13):7563-8.

14. Jamali F. Pharmacokinetics of enantiomers of chiral non-steroidal anti-inflammatory drugs. Eur J Drug Metab Pharmacokinet.1988 Jan-Mar;13(1):1-9.

15. Mehvar R, Jamali F. Pharmacokinetic analysis of the enantiomeric inversion of chiral nonsteroidal antiinflammatory drugs. Pharm Research. 1988 Feb;5(2):76-9.

16. Jamali F, Lovlin R, Aberg G. Bi-directional chiral inversion of ketoprofen in CD-1 mice. Chirality. 1997;9(1):29-31.

17. Poddubnyy D, Song IH, Sieper J. A systematic comparison of rheumatoid arthritis and ankylosing spondylitis: non-steroidal anti-inflammatory drugs. Clin Exp Rheumatol. 2009 Jul-Aug;27(4 Suppl 55):S148-51.

18. McCarberg B, Tenzer P. Complexities in the pharmacologic management of osteoarthritis pain. Current medical research and opinion. 2013 Apr 3.

19. American Society of Hospital P, American Society of Health System P, Teton Data S, Stat!Ref electronic medical 1. AHFS drug information. Bethesda, MD: American Society of Health-System Pharmacists, Inc; 2010.

20. Nishihara R, Lochhead P, Kuchiba A, Jung S, Yamauchi M, Liao X, et al. Aspirin use and risk of colorectal cancer according to BRAF mutation status. JAMA. 2013 Jun 26;309(24):2563-71.

21. Cote S, Carmichael PH, Verreault R, Lindsay J, Lefebvre J, Laurin D. Nonsteroidal antiinflammatory drug use and the risk of cognitive impairment and Alzheimer's disease. Alzheimer's \& dementia: J Alzheimer Asso. 2012 May;8(3):219-26.

22. Arvanitakis Z, Grodstein F, Bienias JL, Schneider JA, Wilson RS, Kelly JF, et al. Relation of NSAIDs to incident $\mathrm{AD}$, change in cognitive function, and AD pathology. Neurology. 2008 Jun 3;70(23):221925.

23. Smyth EM, Grosser T, Wang M, Yu Y, FitzGerald GA. Prostanoids in health and disease. J Lipid Res. 2009 Apr;50 Suppl:S423-8.

24. Fitzgerald GA. Prostaglandins, Aspirin, and Related Compounds. In: Goldman L, Ausiello D, editors. Cecil Textbook of Medicine: Elsevier Science
Health Science div; 2003.

25. Shibata M, Kodani I, Osaki M, Araki K, Adachi H, Ryoke K, et al. Cyclo-oxygenase-1 and -2 expression in human oral mucosa, dysplasias and squamous cell carcinomas and their pathological significance. Oral Oncol. 2005;41(3):304-12.

26. Martel-Pelletier J, Pelletier JP, Fahmi H. New insights into prostaglandin biology. J Rheumatol. 2004;31(1):14-6.

27. Rao P, Knaus EE. Evolution of nonsteroidal antiinflammatory drugs (NSAIDs): cyclooxygenase (COX) inhibition and beyond. J Pharm Pharm Sci. 2008;11(2):81s-110s.

28. Chandrasekharan NV, Dai H, Roos KL, Evanson NK, Tomsik J, Elton TS, et al. COX-3, a cyclooxygenase-1 variant inhibited by acetaminophen and other analgesic/antipyretic drugs: cloning, structure, and expression. ProcNatlAcadSci USA. 2002;99(21):13926-31.

29. Davies NM, Good RL, Roupe KA, Yanez JA. Cyclooxygenase-3: axiom, dogma, anomaly, enigma or splice error?--Not as easy as 1, 2, 3. J Pharm Pharm Sci. 2004 Jul 9;7(2):217-26.

30. Meade EA, Smith WL, DeWitt DL. Differential inhibition of prostaglandin endoperoxide synthase (cyclooxygenase) isozymes by aspirin and other non-steroidal anti-inflammatory drugs. J Biol Chem. 1993 Mar 25;268(9):6610-4.

31. Harirforoosh S, Jamali F. Effect of nonsteroidal antiinflammatory drugs with varying extent of COX-2COX-1 selectivity on urinary sodium and potassium excretion in the rat. Can J Physiol Pharmacol. 2005 Jan;83(1):85-90.

32. Harirforoosh S, Aghazadeh-Habashi A, Jamali F. Extent of renal effect of cyclo-oxygenase-2-selective inhibitors is pharmacokinetic dependent. Clin Exp Pharmacol Physiol. 2006 Oct;33(10):917-24.

33. Gosepath J, Brieger E. Gletsou E, Mann W J. Expression and localization of cyclooxigenases (Cox-1 and Cox-2) in nasal respiratory mucosa. Does Cox-2 play a key role in the immunology of nasal polyps? J Invest Allergol Clin Immunol 2004; 14(2): 114-118.

34. Zidar N, Odar K, Glavac D, Jerse M, Zupanc T, Stajer D. Cyclooxygenase in normal human tissues-is COX-1 really a constitutive isoform, and $\mathrm{COX}-2$ an inducible isoform? J Cell Mol Med. 2009 Sep;13(9B):3753-63.

35. Khan KN, Stanfield KM, Dannenberg A, Seshan $\mathrm{SV}$, Baergen RN, Baron DA, et al. Cyclooxygenase2 expression in the developing human kidney. Pediatr Develop Pathol. 2001 Sep-Oct;4(5):461-6.

36. Antonucci R, Cuzzolin L, Arceri A, Dessi A, Fanos V. Changes in urinary PGE2 after ibuprofen treatment in preterm infants with patent ductus arteriosus. Eur I Clin Pharmacol. 2009 
Mar;65(3):223-30.

37. Claria J. Cyclooxygenase-2 biology. Curr Pharm Design. 2003;9(27):2177-90.

38. Olesen ET, Fenton RA. Is there a role for PGE2 in urinary concentration? J Am Soc Nephrol. 2013 Feb;24(2):169-78.

39. Lioubov I. Brueggemann BKM, Alexander R. Mackie, Leanne L. Cribbs, and, Byron KL. Novel Actions of Nonsteroidal Anti-Inflammatory Drugs on Vascular Ion Channels: Accounting for Cardiovascular Side Effects and Identifying New Therapeutic Applications Mol Cell Pharmacol. 2010;2(1):15-9.

40. Ellis GA, Blake DR. Why are non-steroidal antiinflammatory drugs so variable in their efficacy? A description of ion trapping. Ann Rheum Dis. 1993 Mar;52(3):241-3.

41. Aghazadeh-Habashi A, Jamali F. Pharmacokinetics of meloxicam administered as regular and fast dissolving formulations to the rat: influence of gastrointestinal dysfunction on the relative bioavailability of two formulations. Eur J Pharm Biopharm. 2008 Nov;70(3):889-94.

42. Mandery K, Bujok K, Schmidt I, Wex T, Treiber G, Malfertheiner $\mathrm{P}$, et al. Influence of cyclooxygenase inhibitors on the function of the prostaglandin transporter organic anion-transporting polypeptide 2A1 expressed in human gastroduodenal mucosa. $\mathrm{J}$ Pharmacol Exp Ther. 2010 Feb;332(2):345-51.

43. Davies NM, Jamali F. Pharmacological protection of NSAID-induced intestinal permeability in the rat: effect of tempo and metronidazole as potential free radical scavengers. Human Exp Toxicol. 1997 Jul;16(7):345-9.

44. Granier M, Massin F, Pasquie JL. Pro- and antiarrhythmic effects of anti-inflammatory drugs. Antiinf anti-allerg Agents Med Chem. 2013 Mar;12(1):83-93.

45. Mason RP, Walter MF, McNulty HP, Lockwood SF, Byun J, Day CA, et al. Rofecoxib increases susceptibility of human LDL and membrane lipids to oxidative damage: a mechanism of cardiotoxicity. J Cardiovasc Pharmacol. 2006;47 Suppl 1:S7-14.

46. Liu JY, Li N, Yang J, Qiu H, Ai D, Chiamvimonvat $\mathrm{N}$, et al. Metabolic profiling of murine plasma reveals an unexpected biomarker in rofecoxibmediated cardiovascular events. Proc Natl Acad Sci USA. 2010 Sep 28;107(39):17017-22.

47. Coxib and traditional NSAID Trialists' (CNT) Collaboration. Vascular and upper gastrointestinal effects of non-steroidal anti-inflammatory drugs: meta-analyses of individual participant data from randomised trials. Lancet. 2013; 382, 769-779.

48. Forman JP, Rimm EB, Curhan GC. Frequency of analgesic use and risk of hypertension among men. Arch Intern Med. 2007 Feb 26;167(4):394-9.
49. Silverstein FE, Faich G, Goldstein JL, Simon LS, Pincus T, Whelton A, et al. Gastrointestinal toxicity with celecoxib vs nonsteroidal anti-inflammatory drugs for osteoarthritis and rheumatoid arthritis: the CLASS study: A randomized controlled trial. Celecoxib Long-term Arthritis Safety Study. JAMA. 2000 Sep 13;284(10):1247-55.

50. Bertagnolli MM, Eagle CJ, Zauber AG, Redston M, Solomon SD, Kim K, et al. Celecoxib for the prevention of sporadic colorectal adenomas. The New Eng J Med. 2006 Aug 31;355(9):873-84.

51. Jones $\mathrm{P}$, Lamdin R. Oral cyclo-oxygenase 2 inhibitors versus other oral analgesics for acute soft tissue injury: systematic review and meta-analysis. Clin Drug Invest. 2010;30(7):419-37.

52. Sostres C, Gargallo CJ, Arroyo MT, Lanas A. Adverse effects of non-steroidal anti-inflammatory drugs (NSAIDs, aspirin and coxibs) on upper gastrointestinal tract. Best Pract Res Clin Gastroenterol. 2010;24(2):121-32.

53. Davies NM, Longstreth J, Jamali F. Misoprostol therapeutics revisited. Pharmacotherapy. 2001 Jan;21(1):60-73.

54. Coyne KS, Margolis MK, Cappelleri JC, Hsieh R, Essex MN, Park PW, et al. Prevalence of gastroprotective agent (GPA) use in adults with arthritis in the United States. Curr Medical Res Opin. 2013 May;29(5):421-33.

55. Le Ray I, Barkun AN, Vauzelle-Kervroedan F, Bardou M. Failure to renew prescriptions for gastroprotective agents to patients on continuous nonsteroidal anti-inflammatory drugs increases rate of upper gastrointestinal injury. Clin Gastroenterol Hepatol. 2013 May;11(5): 499-504.

56. Kellner HL, Li C, Essex MN. Efficacy and safety of celecoxib versus diclofenac and omeprazole in elderly arthritis patients: a subgroup analysis of the CONDOR trial. Curr Med Res Opin. 2012 Sep;28(9):1537-45.

57. Jarupongprapa S, Ussavasodhi P, Katchamart W. Comparison of gastrointestinal adverse effects between cyclooxygenase- 2 inhibitors and nonselective, non-steroidal anti-inflammatory drugs plus proton pump inhibitors: a systematic review and meta-analysis. J Gastroenterol. 2013 Jul;48(7):8308.

58. Laine L, Smith R, Min K, Chen C, Dubois RW. Systematic review: the lower gastrointestinal adverse effects of non-steroidal anti-inflammatory drugs. Aliment Pharmacol Ther. 2006 Sep 1;24(5):751-67.

59. De Petris G, Lopez JI. Histopathology of diaphragm disease of the small intestine: a study of 10 cases from a single institution. Am J Clin Pathol. 2008 Oct;130(4):518-25.

60. Laine L, Curtis SP, Langman M, Jensen DM, Cryer 
B, Kaur A, et al. Lower gastrointestinal events in a double-blind trial of the cyclo-oxygenase-2 selective inhibitor etoricoxib and the traditional nonsteroidal anti-inflammatory drug diclofenac. Gastroenterology. 2008 Nov;135(5):1517-25.

61. Lake H. Ibuprofen belly: A case of small bowel stricture due to non-steroidal anti-inflammatory drug abuse in the setting of codeine dependence. Aust $N$ Z J Psychiatry. 2013; 47: 1210-1211.

62. Nadatani Y, Watanabe T, Tanigawa T, Sogawa M, Yamagami H, Shiba M, et al. Incidence and risk factors of gastrointestinal bleeding in patients on low-dose aspirin therapy after percutaneous coronary intervention in Japan. Scand J Gastroenterol. 2013 Mar;48(3):320-5.

63. Curtis JR, Lanas A, John A, Johnson DA, Schulman KL. Factors associated with gastrointestinal perforation in a cohort of patients with rheumatoid arthritis. Arthritis Care Res. 2012 Dec;64(12):181928.

64. Davies NM. Sustained release and enteric coated NSAIDs: are they really GI safe? J Pharm Pharm Sci. 1999 Jan-Apr;2(1):5-14.

65. Davies NM, Jamali F. Influence of dosage form on the gastroenteropathy of flurbiprofen in the rat: evidence of shift in the toxicity site. Pharm Res. 1997 Nov;14(11):1597-600.

66. Khazaeinia T, Jamali F. Evaluation of gastrointestinal toxicity of ibuprofen using surrogate markers in rats: effect of formulation and route of administration. Clin Exp Rheumatol. 2000 MarApr;18(2):187-92.

67. Vonkeman HE, van de Laar MA. Nonsteroidal antiinflammatory drugs: adverse effects and their prevention. Sem Arthritis Rheumat. 2010 Feb;39(4):294-312.

68. Fujimori S, Takahashi Y, Gudis K, Seo T, Ehara A, Kobayashi $\mathrm{T}$, et al. Rebamipide has the potential to reduce the intensity of NSAID-induced small intestinal injury: a double-blind, randomized, controlled trial evaluated by capsule endoscopy. J Gastroenterol. 2011 Jan;46(1):57-64.

69. Fujimori S, Seo T, Gudis K, Ehara A, Kobayashi T, Mitsui K, et al. Prevention of nonsteroidal antiinflammatory drug-induced small-intestinal injury by prostaglandin: a pilot randomized controlled trial evaluated by capsule endoscopy. Gastrointest Endosc. 2009 Jun;69(7):1339-46.

70. Laine L, Kivitz AJ, Bello AE, Grahn AY, Schiff $\mathrm{MH}$, Taha AS. Double-blind randomized trials of single-tablet ibuprofen/high-dose famotidine vs. ibuprofen alone for reduction of gastric and duodenal ulcers. Am J Gastroenterol. 2012 Mar;107(3):379-86.

71. Wang X, Tian HJ, Yang HK, Wanyan P, Peng YJ. Meta-analysis: cyclooxygenase-2 inhibitors are no better than nonselective nonsteroidal antiinflammatory drugs with proton pump inhibitors in regard to gastrointestinal adverse events in osteoarthritis and rheumatoid arthritis. Eur J Gastroenterol Hepatol. 2011 Oct;23(10):876-80.

72. Satoh H, Takeuchi K. Management of NSAID/aspirin-induced small intestinal damage by GI-sparing NSAIDs, anti-ulcer drugs and food constituents. Curr Med Chem. 2012;19(1):82-9.

73. Hunt RH, Lanas A, Stichtenoth DO, Scarpignato C. Myths and facts in the use of anti-inflammatory drugs. Ann Med. 2009;41(6):423-37.

74. Klinge SA, Sawyer GA. Effectiveness and safety of topical versus oral nonsteroidal anti-inflammatory drugs: a comprehensive review. Physic Sport Med. 2013 May;41(2):64-74.

75. Brewer AR, Pierchala LA, Yanchick JK, Magelli M, Rovati S. Gastrointestinal tolerability of diclofenac epolamine topical patch $1.3 \%$ : a pooled analysis of 14 clinical studies. Postgrad Med. 2011 Jul;123(4):168-76.

76. McCormack PL. Celecoxib: a review of its use for symptomatic relief in the treatment of osteoarthritis, rheumatoid arthritis and ankylosing spondylitis. Drugs. 2011 Dec 24;71(18):2457-89.

77. Graham DY, Jewell NP, Chan FK. Rofecoxib and clinically significant upper and lower gastrointestinal events revisited based on documents from recent litigation. Am J Med Sci. 2011 Nov;342(5):356-64.

78. Marra CA, Lynd LD, Colley L, Harvard SS, Lacaille $\mathrm{D}$, Schwenger $\mathrm{E}$, et al. Risk of gastrointestinal events in patients with rheumatoid arthritis after withdrawal of rofecoxib. J Rheumatol. 2012 May;39(5):910-5.

79. Mallen SR, Essex MN, Zhang R. Gastrointestinal tolerability of NSAIDs in elderly patients: a pooled analysis of 21 randomized clinical trials with celecoxib and nonselective NSAIDs. Curr Med Res Opin. $2011 \mathrm{Jul} ; 27(7): 1359-66$.

80. Musu M, Finco G, Antonucci R, Polati E, Sanna D, Evangelista $M$, et al. Acute nephrotoxicity of NSAID from the foetus to the adult. Eur Review Med Pharmacol Sci. 2011 Dec;15(12):1461-72.

81. Breyer MD, Harris RC. Cyclooxygenase 2 and the kidney. Curr Opin Nephrol Hypertens. 2001;10(1):89-98.

82. Whelton A, Hamilton CW. Nonsteroidal antiinflammatory drugs: effects on kidney function. J Clin Pharmacol. 1991;31(7):588-98.

83. Hegazy R, Alashhab M, Amin M. Cardiorenal Effects of Newer NSAIDs (Celecoxib) versus Classic NSAIDs (Ibuprofen) in Patients with Arthritis. J Toxicol. 2011;2011:862153.

84. Anavekar NS, McMurray JJ, Velazquez EJ, Solomon SD, Kober L, Rouleau JL, et al. Relation 
between renal dysfunction and cardiovascular outcomes after myocardial infarction. N Engl J Med. 2004;351(13):1285-95.

85. Vieux R, Desandes R, Boubred F, Semama D, Guillemin F, Buchweiller MC, et al. Ibuprofen in very preterm infants impairs renal function for the first month of life. Pediatr Nephrol. 2010 Feb;25(2):267-74.

86. Benson P, Yudd M, Sims D, Chang V, Srinivas S, Kasimis B. Renal effects of high-dose celecoxib in elderly men with stage D2 prostate carcinoma. Clin Nephrol. 2012 Nov;78(5):376-81.

87. Blann AD, Kuzniatsova N, Velu S, Lip GY. Renal function and aspirin resistance in patients with coronary artery disease. Thrombosis Res. 2012 Sep;130(3):e103-6.

88. Wei L, MacDonald TM, Jennings C, Sheng X, Flynn RW, Murphy MJ. Estimated GFR reporting is associated with decreased nonsteroidal antiinflammatory drug prescribing and increased renal function. Kidney Inter. 2013 Jul;84(1):174-8.

89. Patel K, Diamantidis C, Zhan M, Hsu VD, Walker $\mathrm{LD}$, Gardner J, et al. Influence of creatinine versus glomerular filtration rate on non-steroidal antiinflammatory drug prescriptions in chronic kidney disease. Am J Nephrol. 2012;36(1):19-26.

90. Lameire N, Van Biesen W, Vanholder R. Acute renal failure. Lancet. 2005 Jan 29-Feb 4;365 (9457):417-30.

91. Pannu N, Nadim MK. An overview of drug-induced acute kidney injury. Critical care medicine. 2008 Apr;36(4 Suppl):S216-23.

92. Fairweather J, Jawad AS. Cardiovascular risk with nonsteroidal anti-inflammatory drugs (NSAIDs): the urological perspective. BJU int. 2012: 110:E437.

93. Dhanvijay P, Misra AK, Varma SK. Diclofenac induced acute renal failure in a decompensated elderly patient. J Pharmacol pharmacother. 2013 Apr;4(2):155-7.

94. Fournier JP, Sommet A, Durrieu G, Poutrain JC, Lapeyre-Mestre M, Montastruc JL. Drug interactions between antihypertensive drugs and non-steroidal anti-inflammatory agents: a descriptive study using the French Pharmacovigilance database. Fundamen Clinical Pharmacol. 2012 Nov 2.

95. Horbach SJ, Lopes RD, da CGJC, Martini F, Mehta $\mathrm{RH}$, Petracco JB, et al. Naproxen as prophylaxis against atrial fibrillation after cardiac surgery: the NAFARM randomized trial. Am J Med. 2011 Nov;124(11):1036-42.

96. Zaki SA, Nilofer AR, Taqi SA. Nimesulide-induced acute renal failure. Saudi J Kidney Dis Transplant. 2012 Nov;23(6):1294-6.

97. Broadis E, Barbour L, O'Toole S, Fyfe A, Flett M, Irwin G, et al. Bilateral ureteric obstruction secondary to renal papillary necrosis. Pediatr Surg
Inter. 2010 Aug;26(8):867-9.

98. Mihovilovic K, Ljubanovic D, Knotek M. Safe administration of celecoxib to a patient with repeated episodes of nephrotic syndrome induced by NSAIDs. Clin Drug investig. 2011;31(5):351-5.

99. Palmer BF. Renal complications associated with use of nonsteroidal anti-inflammatory agents. J Investig Med. 1995;43(6):516-33.

100.Schwartz JI, Vandormael K, Malice MP, Kalyani RN, Lasseter KC, Holmes GB, et al. Comparison of rofecoxib, celecoxib, and naproxen on renal function in elderly subjects receiving a normal-salt diet. Clin Pharmacol Ther. 2002;72(1):50-61.

101.Fernandez-Llama P, Ecelbarger CA, Ware JA, Andrews P, Lee AJ, Turner R, et al. Cyclooxygenase inhibitors increase $\mathrm{Na}-\mathrm{K}-2 \mathrm{Cl}$ cotransporter abundance in thick ascending limb of Henle's loop. Am J Physiol. 1999;277(2 Pt 2):F219-F26.

102. Whelton A, Maurath CJ, Verburg KM, Geis GS. Renal safety and tolerability of celecoxib, a novel cyclooxygenase-2 inhibitor. Am J Ther. 2000; 7(3):159-75.

103.Catella-Lawson F, McAdam B, Morrison BW, Kapoor S, Kujubu D, Antes L, et al. Effects of specific inhibition of cyclooxygenase-2 on sodium balance, hemodynamics, and vasoactive eicosanoids. J Pharmacol ExpTher. 1999;289(2):735-41.

104. Kamperis K, Rittig S, Bower WF, Djurhuus JC. Effect of indomethacin on desmopressin resistant nocturnal polyuria and nocturnal enuresis. J Urolog. 2012 Nov; 188(5):1915-22.

105.Balas M, Plakogiannis R, Sinnett M. Periorbital edema associated with separate courses of ibuprofen and naproxen. Am J Health-Syst Pharm. 2010 Jun 1;67(11):906-9.

106. Wenner MM, Edwards DG, Ray CA, Rose WC, Gardner TJ, Stillabower M, et al. Celecoxib does not alter cardiovascular and renal function during dietary salt loading. Clin Exp Pharmacol Physiol. 2011 Aug;38(8):543-9.

107.Lafrance JP, Miller DR. Dispensed selective and nonselective nonsteroidal anti-inflammatory drugs and the risk of moderate to severe hyperkalemia: a nested case-control study. Am J Kidney Dis. 2012 Jul;60(1):82-9.

108. Stichtenoth DO, Frolich JC. COX-2 and the kidneys. Curr Pharm Des. 2000;6(17):1737-53.

109. Brater DC. Effects of nonsteroidal antiinflammatory drugs on renal function: focus on cyclooxygenase-2-selective inhibition. Am J Med. 1999;107(6A):65S-70S.

110.Platts-Mills TF, Richmond NL, Hunold KM, Bowling CB. Life-threatening hyperkalemia after 2 days of ibuprofen. Am J Emerg Med. 2013 Feb;31(2):465 e1-2.

111.Lam Q, Schneider HG. Hyperkalaemia with 
cyclooxygenase-2 inhibition and hypoaldosteronism. Inter Med J. 2005 Sep;35(9):572-3.

112.Aljadhey H, Tu W, Hansen RA, Blalock S, Brater DC, Murray MD. Risk of hyperkalemia associated with selective COX-2 inhibitors. Pharmacoepidemiol Drug Saf. 2010 Nov;19 (11):1194-8.

113. Katekao W, Yamwong S, Nathisuwan S, Likittanasombat K. Retrospective cohort study of association of NSAIDS exposure and outcome of acute decompensated congestive heart failure. J Med Assoc Thailand. 2013 Apr;96(4):423-31.

114.Ejaz P, Bhojani K, Joshi VR. NSAIDs and kidney. J Assoc Physicians India. 2004 Aug;52:632-40.

115.Nderitu P, Doos L, Jones PW, Davies SJ, Kadam UT. Non-steroidal anti-inflammatory drugs and chronic kidney disease progression: a systematic review. Fam Prac. 2013 Jun;30(3):247-55.

116. Sturmer T, Erb A, Keller F, Gunther KP, Brenner H. Determinants of impaired renal function with use of nonsteroidal anti-inflammatory drugs: the importance of half-life and other medications. Am J Med. 2001 Nov;111(7):521-7.

117. Snowden S, Nelson R. The effects of nonsteroidal anti-inflammatory drugs on blood pressure in hypertensive patients. Cardiol Review. 2011 JulAug;19(4):184-91.

118. Mackenzie IS, MacDonald TM. Treatment of osteoarthritis in hypertensive patients. Expert opin Pharmacothe. 2010 Feb;11(3):393-403.

119.Grossman E, Messerli FH. Drug-induced hypertension: an unappreciated cause of secondary hypertension. Am J Med. 2012 Jan;125(1):14-22.

120.Sudano I, Flammer AJ, Roas S, Enseleit F, Noll G, Ruschitzka F. Nonsteroidal antiinflammatory drugs, acetaminophen, and hypertension. Curr Hypertens Rep. 2012 Aug;14(4):304-9.

121.Zhang J, Ding EL, Song Y. Adverse effects of cyclooxygenase 2 inhibitors on renal and arrhythmia events: meta-analysis of randomized trials. JAMA. 2006 Oct 4;296(13):1619-32.

122.Chan CC, Reid CM, Aw TJ, Liew D, Haas SJ, Krum H. Do COX-2 inhibitors raise blood pressure more than nonselective NSAIDs and placebo? An updated meta-analysis. J Hypertension. 2009 Dec;27(12):2332-41.

123. Montgomery BD. Analgesic use and risk of hypertension: concern about bias. Arch Intern Med. 2007 Nov 26;167(21):2368-9.

124.Udell E. Another possible cause of increased blood pressure in men older than 60 years who are taking medications to control musculoskeletal pain. Arch Intern Med. 2007 Nov 26;167(21):2371;

125.Jamali F. Arthritis is associated with cardiovascular disease in the users of analgesics and nonsteroidal anti-inflammatory drugs. Arch Intern Med. 2007
Nov 26;167(21):2371-2;

126. Kleinert S, Krueger K. [Cardiovascular comorbidity and its risk factors in rheumatoid arthritis]. Z Rheumatol. 2011 Aug;70(6):464-72.

127.Mutru O, Laakso M, Isomaki H, Koota K. Ten year mortality and causes of death in patients with rheumatoid arthritis. Br Med J (Clin Res Ed). 1985 Jun 15;290(6484):1797-9.

128. Maradit-Kremers H, Nicola PJ, Crowson CS, Ballman KV, Gabriel SE. Cardiovascular death in rheumatoid arthritis: a population-based study. Arthritis Rheum.2005 Mar;52(3):722-32.

129. Mayo PR, Skeith K, Russell AS, Jamali F. Decreased dromotropic response to verapamil despite pronounced increased drug concentration in rheumatoid arthritis. B J Clin Pharmacol. 2000 Dec;50(6):605-13.

130.Bombardier C, Laine L, Reicin A, Shapiro D, Burgos-Vargas R, Davis B, et al. Comparison of upper gastrointestinal toxicity of rofecoxib and naproxen in patients with rheumatoid arthritis. VIGOR Study Group. N Engl J Med. 2000;343(21):1520-8, 2.

131.Bresalier RS, Sandler RS, Quan H, Bolognese JA, Oxenius B, Horgan K, et al. Cardiovascular events associated with rofecoxib in a colorectal adenoma chemoprevention trial. $\mathrm{N}$ Engl $\mathrm{J}$ Med. 2005;352(11):1092-102.

132.Review: Studies on the cardiovascular effects of selective COX-2 inhibitors show mixed results. ACP J Club. 2002;136(2):53.

133. Mukherjee D, Nissen SE, Topol EJ. Risk of cardiovascular events associated with selective COX-2 inhibitors. JAMA. 2001 Aug 22-29; 286(8):954-9.

134.Curfman GD, Morrissey S, Drazen JM. Expression of concern: Bombardier et al., "Comparison of upper gastrointestinal toxicity of rofecoxib and naproxen in patients with rheumatoid arthritis," N Engl J Med 2000;343:1520-8. N Engl J Med. 2005; 353 (26):2813-4.

135. Combe B, Swergold G, McLay J, McCarthy T, Zerbini C, Emery P, et al. Cardiovascular safety and gastrointestinal tolerability of etoricoxib vs diclofenac in a randomized controlled clinical trial (The MEDAL study). Rheumatology. 2009 Apr;48(4):425-32.

136. Gislason GH, Rasmussen JN, Abildstrom SZ, Schramm TK, Hansen ML, Fosbol EL, et al. Increased mortality and cardiovascular morbidity associated with use of nonsteroidal antiinflammatory drugs in chronic heart failure. Arch Intern Med. 2009;169(2):141-9.

137.Liu SS, Bae JJ, Bieltz M, Ma Y, Memtsoudis S. Association of perioperative use of nonsteroidal 
anti-inflammatory drugs with postoperative myocardial infarction after total joint replacement. Region Anesthes Pain Med. 2012 Jan-Feb;37(1):4550.

138. Mangoni AA, Woodman RJ, Gaganis P, Gilbert AL, Knights KM. Use of non-steroidal anti-inflammatory drugs and risk of incident myocardial infarction and heart failure, and all-cause mortality in the Australian veteran community. Brit J Clin Pharmacol.2010 Jun;69(6):689-700.

139. De Caterina R, Ruigomez A, Rodriguez LA. Longterm use of anti-inflammatory drugs and risk of atrial fibrillation. Arch Intern Med. 2010 Sep 13;170(16):1450-5.

140.Chao TF, Liu CJ, Chen SJ, Wang KL, Lin YJ, Chang SL, et al. The association between the use of non-steroidal anti-inflammatory drugs and atrial fibrillation: A nationwide case-control study. Inter $\mathbf{J}$ Cardiol. 2012 Oct 6.

141.Schmidt M, Christiansen CF, Mehnert F, Rothman KJ, Sorensen HT. Non-steroidal anti-inflammatory drug use and risk of atrial fibrillation or flutter: population based case-control study. Brit Med J. 2011;343:d3450.

142.Varas-Lorenzo C, Castellsague J, Stang MR, PerezGutthann S, Aguado J, Rodriguez LA. The use of selective cyclooxygenase-2 inhibitors and the risk of acute myocardial infarction in Saskatchewan, Canada. Pharmacoepidemiol Drug Saf. 2009 Nov;18(11):1016-25.

143. Fosbol EL, Folke F, Jacobsen S, Rasmussen JN, Sorensen R, Schramm TK, et al. Cause-specific cardiovascular risk associated with nonsteroidal anti-inflammatory drugs among healthy individuals. Circulation Cardiovascular quality and outcomes. $2010 \mathrm{Jul} ; 3(4): 395-405$.

144.Renner B, Brune K. Are myocardial infarctions and death in healthy individuals associated with the use of cyclooxygenase inhibitors? Clin Pharmacol Ther. 2009 Dec;86(6):599-600; author reply 2-4.

145.van Beers EJ, de Groot JR, Tijssen JG. Do NSAIDs actually protect against myocardial infarction and death? Clin Pharmacol Ther. 2009 Dec;86(6):601-2.

146. Moore N. No obvious extra cardiovascular risk associated with low-dose NSAIDs. Clin Pharmacol ther. 2009 Dec;86(6):600-1.

147.Fosbol EL, Gislason GH, Jacobsen S, Folke F, Hansen ML, Schramm TK, et al. Risk of myocardial infarction and death associated with the use of nonsteroidal anti-inflammatory drugs (NSAIDs) among healthy individuals: a nationwide cohort study. Clin Pharmacol Ther. 2009 Feb;85(2):190-7.

148.Garcia Rodriguez LA, Tacconelli S, Patrignani P. Role of Dose Potency in the Prediction of Risk of Myocardial Infarction Associated with Nonsteroidal Anti-Inflammatory Drugs in the General Population.
J Am Coll Cardiol. 2008;52(20):1628-36.

149.Levesque LE, Brophy JM, Zhang B. The risk for myocardial infarction with cyclooxygenase-2 inhibitors: a population study of elderly adults. Ann Intern Med. 2005 Apr 5;142(7):481-9.

150.Kerr SJ, Rowett DS, Sayer GP, Whicker SD, Saltman DC, Mant A. All-cause mortality of elderly Australian veterans using COX-2 selective or nonselective NSAIDs: a longitudinal study. Br J Clin Pharmacol. 2011;71(6):936-42.

151.Goodson NJ, Brookhart AM, Symmons DPM, Silman AJ, Solomon DH. Non-steroidal antiinflammatory drug use does not appear to be associated with increased cardiovascular mortality in patients with inflammatory polyarthritis: Results from a primary care based inception cohort of patients. Ann Rheum Dis. 2009;68(3):367-72.

152.Lindhardsen J, Gislason GH, Jacobsen S, Ahlehoff O, Olsen AM, Madsen OR, et al. Non-steroidal antiinflammatory drugs and risk of cardiovascular disease in patients with rheumatoid arthritis: a nationwide cohort study. Ann Rheum Dis. 2013 Jun 8. Epub ahead of print.

153.Zell JA, Ziogas A, Bernstein L, Clarke CA, Deapen D, Largent JA, et al. Nonsteroidal anti-inflammatory drugs: effects on mortality after colorectal cancer diagnosis. Cancer. 2009;115(24):5662-71.

154.Grimaldi-Bensouda L, Rossignol M, Danchin N, Steg PG, Bessede G, Ovize M, et al. Risk of ST versus non-ST elevation myocardial infarction associated with non-steroidal anti-inflammatory drugs. Heart. 2011 Nov;97(22):1834-40.

155.Shiri R, Koskimaki J, Hakkinen J, Tammela TL, Auvinen A, Hakama M. Effect of nonsteroidal antiinflammatory drug use on the incidence of erectile dysfunction. J Urolog. 2006 May;175(5):1812-5; discussion 5-6.

156. Johnsen SP, Larsson H, Tarone RE, McLaughlin JK, Norgard B, Friis S, et al. Risk of hospitalization for myocardial infarction among users of rofecoxib, celecoxib, and other NSAIDs: a population-based case-control study. Arch Intern Med. 2005 May 9;165(9):978-84.

157.Hippisley-Cox J, Coupland C. Risk of myocardial infarction in patients taking cyclo-oxygenase- 2 inhibitors or conventional non-steroidal antiinflammatory drugs: Population based nested casecontrol analysis. $\mathrm{Br}$ Med $\mathrm{J}$ (Clin Res $\mathrm{Ed}$ ). 2005;330(7504):1366-9.

158.Helin-Salmivaara A, Virtanen A, Vesalainen R, Gronroos JM, Klaukka T, Idanpaan-Heikkila JE, et al. NSAID use and the risk of hospitalization for first myocardial infarction in the general population: A nationwide case-control study from Finland. Eur Heart J. 2006;27(14):1657-63.

159.Reiss AB, Anwar F, Chan ES, Anwar K. Disruption 
of cholesterol efflux by COXIB medications and inflammatory processes: link to increased cardiovascular risk. J Investig Med. 2009;57(6):695702.

160. Roumie CL, Choma NN, Kaltenbach L, Mitchel EF, Jr., Arbogast PG, Griffin MR. Non-aspirin NSAIDs, cyclooxygenase-2 inhibitors and risk for cardiovascular events-stroke, acute myocardial infarction, and death from coronary heart disease. Pharmacoepidemiol Drug Saf. 2009;18(11):1053-63.

161. Varas-Lorenzo C, Riera-Guardia N, Calingaert B, Castellsague J, Salvo F, Nicotra F, et al. Myocardial infarction and individual nonsteroidal antiinflammatory drugs meta-analysis of observational studies. Pharmacoepidemiol Drug Saf. 2013 Apr 25.

162. Trelle S, Reichenbach S, Wandel S, Hildebrand P, Tschannen B, Villiger PM, et al. Cardiovascular safety of non-steroidal anti-inflammatory drugs: network meta-analysis. Brit M J. 2011;342:c7086.

163. Solomon DH, Schneeweiss S, Glynn RJ, Kiyota Y, Levin R, Mogun H, et al. Relationship between selective cyclooxygenase-2 inhibitors and acute myocardial infarction in older adults. Circulation.2004 May 4;109(17):2068-73.

164. Vaithianathan R, Hockey PM, Moore TJ, Bates DW. Iatrogenic effects of COX-2 inhibitors in the US population: findings from the Medical Expenditure Panel Survey. Drug Saf. 2009;32(4):335-43.

165.Schjerning Olsen AM, Fosbol EL, Lindhardsen J, Folke F, Charlot M, Selmer C, et al. Duration of treatment with nonsteroidal anti-inflammatory drugs and impact on risk of death and recurrent myocardial infarction in patients with prior myocardial infarction: a nationwide cohort study. Circulation. 2011;123(20):2226-35.

166. Brophy JM, Levesque LE, Zhang B. The coronary risk of cyclo-oxygenase-2 inhibitors in patients with a previous myocardial infarction. Heart. 2007 Feb;93(2):189-94.

167.Lanas A, Tornero J, Zamorano JL. Assessment of gastrointestinal and cardiovascular risk in patients with osteoarthritis who require NSAIDs: the LOGICA study. Ann Rheum Dis. 2010 Aug;69(8):1453-8.

168. Gislason GH, Jacobsen S, Rasmussen JN, Rasmussen S, Buch P, Friberg J, et al. Risk of death or reinfarction associated with the use of selective cyclooxygenase-2 inhibitors and nonselective nonsteroidal antiinflammatory drugs after acute myocardial infarction. Circulation. 2006 Jun 27;113(25):2906-13.

169.Rahme E, Watson DJ, Kong SX, Toubouti Y, LeLorier J. Association between nonnaproxen NSAIDs, COX-2 inhibitors and hospitalization for acute myocardial infarction among the elderly: a retrospective cohort study. Pharmacoepidemiol
Drug Saf. 2007 May;16(5):493-503.

170.Warner JJ, Weideman RA, Kelly KC, Brilakis ES, Banerjee S, Cunningham F, et al. The risk of acute myocardial infarction with etodolac is not increased compared to naproxen: a historical cohort analysis of a generic COX-2 selective inhibitor. J Cardiovasc Pharmacol Ther. 2008 Dec;13(4):252-60.

171.Caughey GE, Roughead EE, Pratt N, Killer G, Gilbert AL. Stroke risk and NSAIDs: an Australian population-based study. Med J Austral. 2011 Nov 7;195(9):525-9.

172. Varas-Lorenzo C, Riera-Guardia N, Calingaert B, Castellsague J, Pariente A, Scotti L, et al. Stroke risk and NSAIDs: a systematic review of observational studies. Pharmacoepidemiol Drug Saf. 2011; 20(12):1225-36.

173. Haag MDM, Bos MJ, Hofman A, Koudstaal PJ, Breteler MMB, Stricker BHC. Cyclooxygenase selectivity of nonsteroidal anti-inflammatory drugs and risk of stroke. Arch Intern Med. 2008;168(11):1219-24.

174.Capone ML, Tacconelli S, Di Francesco L, Petrelli M, Patrignani P. Cardiovascular effects of valdecoxib: Transducing human pharmacology results into clinical read-outs. Expert Opin Drug Saf. 2008;7(1):29-42.

175.Ross JS, Madigan D, Hill KP, Egilman DS, Wang Y, Krumholz HM. Pooled analysis of rofecoxib placebo-controlled clinical trial data: lessons for postmarket pharmaceutical safety surveillance. Arch Intern Med. 2009;169(21):1976-85.

176.Singh G, Lanes S, Triadafilopoulos G. Risk of serious upper gastrointestinal and cardiovascular thromboembolic complications with meloxicam. Am J Med. 2004;117(2):100-6.

177.Bertagnolli MM, Eagle CJ, Zauber AG, Redston M, Breazna A, Kim K, et al. Five-year efficacy and safety analysis of the Adenoma Prevention with Celecoxib Trial. Cancer Prevent Res. 2009;2(4):31021.

178. Layton D, Hughes K, Harris S, Shakir SA. Comparison of the incidence rates of thromboembolic events reported for patients prescribed celecoxib and meloxicam in general practice in England using Prescription-Event Monitoring (PEM) data. Rheumatology.2003 Nov;42(11):1354-64.

179. Kearney PM, Baigent C, Godwin J, Halls H, Emberson JR, Patrono C. Do selective cyclooxygenase- 2 inhibitors and traditional non-steroidal anti-inflammatory drugs increase the risk of atherothrombosis? Brit M J. 2006;332(7553):13028.

180.Clements JD, Jamali F. Pravastatin reverses the down-regulating effect of inflammation on betaadrenergic receptors: a disease-drug interaction 
between inflammation, pravastatin, and propranolol. Vascular Pharmacol. 2007 Jan;46(1):52-9.

181.Clements JD, Jamali F. Norepinephrine transporter is involved in down-regulation of beta1-adrenergic receptors caused by adjuvant arthritis. J Pharm Pharm Sci. 2009;12(3):337-45.

182.Jamali AH, Tang WH, Khot UN, Fowler MB. The role of angiotensin receptor blockers in the management of chronic heart failure. Arch Intern Med. 2001 Mar 12;161(5):667-72.

183.Dagenais NJ, Jamali F. Protective effects of angiotensin II interruption: evidence for antiinflammatory actions. Pharmacother. 2005 Sep;25(9):1213-29.

184. Hanafy S, Dagenais NJ, Dryden WF, Jamali F. Effects of angiotensin II blockade on inflammationinduced alterations of pharmacokinetics and pharmacodynamics of calcium channel blockers. Brit J Pharmacol. 2008 Jan;153(1):90-9.

185. Grosser T, Fries S, FitzGerald GA. Biological basis for the cardiovascular consequences of $\mathrm{COX}-2$ inhibition: therapeutic challenges and opportunities. J Clin Invest. 2006 Jan;116(1):4-15.

186.Yu Z, Crichton I, Tang SY, Hui Y, Ricciotti E, Levin MD, et al. Disruption of the 5-lipoxygenase pathway attenuates atherogenesis consequent to COX-2 deletion in mice. Proc Natl Acad Sci U S A.. 2012 Apr 24;109(17):6727-32.

187.Aljadhey H, Tu W, Hansen RA, Blalock SJ, Brater DC, Murray MD. Comparative effects of nonsteroidal anti-inflammatory drugs (NSAIDs) on blood pressure in patients with hypertension. BMC Cardiovasc Disord.2012;12:93.

188. Krum H, Swergold G, Curtis SP, Kaur A, Wang H, Smugar SS, et al. Factors associated with blood pressure changes in patients receiving diclofenac or etoricoxib: results from the MEDAL study. J Hypertens. 2009;27(4):886-93.

189. White WB, Schnitzer TJ, Fleming R, Duquesroix B, Beekman M. Effects of the cyclooxygenase inhibiting nitric oxide donator naproxcinod versus naproxen on systemic blood pressure in patients with osteoarthritis. Am J Cardiolog. 2009; 104(6):840-5.

190.Elliott WJ. Do the blood pressure effects of nonsteroidal antiinflammatory drugs influence cardiovascular morbidity and mortality? Curr Hypertens Rep. 2010;12(4):258-66.

191. Whelton A, Fort JG, Puma JA, Normandin D, Bello AE, Verburg KM. Cyclooxygenase-2--specific inhibitors and cardiorenal function: a randomized, controlled trial of celecoxib and rofecoxib in older hypertensive osteoarthritis patients. Am J Ther. 2001 Mar-Apr;8(2):85-95.

192. Khan M, Fraser A. Cox-2 inhibitors and the risk of cardiovascular thrombotic events. Ir Med J.2012 Apr;105(4):119-21.

193.Aghazadeh-Habashi A, Jamali F. The glucosamine controversy; a pharmacokinetic issue. J Pharm Pharm Sci. 2011;14(2):264-73.

194. Rovati GE, Sala A, Capra V, Dahlen SE, Folco G. Dual COXIB/TP antagonists: a possible new twist in NSAID pharmacology and cardiovascular risk. Trends Pharmacol Sci. 2010 Mar;31(3):102-7.

195.Anzini M, Di Capua A, Valenti S, Brogi S, Rovini M, Giuliani G, et al. Novel analgesic/antiinflammatory agents: 1,5-diarylpyrrole nitrooxyalkyl ethers and related compounds as cyclooxygenase- 2 inhibiting nitric oxide donors. J Med Chem. 2013 Apr 25;56(8):3191-206.

196.Knights KM, Mangoni AA, Miners JO. Defining the COX inhibitor selectivity of NSAIDs: implications for understanding toxicity. Expert Rev Clin Pharmacol. 2010 Nov;3(6):769-76.

197. Wyatt JE, Pettit WL, Harirforoosh S. Pharmacogenetics of nonsteroidal anti-inflammatory drugs. Pharmacogenom J. 2012 Dec;12(6):462-7.

198. St Germaine CG, Bogaty P, Boyer L, Hanley J, Engert JC, Brophy JM. Genetic polymorphisms and the cardiovascular risk of non-steroidal antiinflammatory drugs. Am J Cardiolog. 2010 Jun 15;105(12):1740-5.

199.Becker MC, Wang TH, Wisniewski L, Wolski K, Libby P, Luscher TF, et al. Rationale, design, and governance of Prospective Randomized Evaluation of Celecoxib Integrated Safety versus Ibuprofen Or Naproxen (PRECISION), a cardiovascular end point trial of nonsteroidal antiinflammatory agents in patients with arthritis. Am Heart J. 2009 Apr;157(4):606-12.

200. Macdonald TM, Mackenzie IS, Wei L, Hawkey CJ, Ford I, SCOT Group Collaborators. Methodology of a large prospective, randomised, open, blinded endpoint streamlined safety study of celecoxib versus traditional non-steroidal anti-inflammatory drugs in patients with osteoarthritis or rheumatoid arthritis: Protocol of the standard care versus celecoxib outcome trial (SCOT). Brit Med J Open. 2013;3(1).

201.Becker JC, Domschke W, Pohle T. Current approaches to prevent NSAID-induced gastropathy - COX selectivity and beyond. Br J Clin Pharmacol. 2004 December; 58(6): 587-600. 